\title{
La VIl-la romana de Parc de les Nacions: Estudi numismàtic dels fons del MUSA (Museu de la Ciutat D’Alacant)
}

The Roman Villa of Parc de les Nacions: Numismatic Study in the MUSA (Museum of the City of Alicante) Collection

\section{IMMACULADA GARRIGÓS I ALBERT ${ }^{1}$}

(1) immagarrigos@gmail.com

\section{RESUM:}

En el següent estudi es presenta el repertori monetari aparegut durant les excavacions arqueològiques de la vil.la romana de Parc de les Nacions (Alacant). Es fa una catalogació de les troballes monetàries que contenen un marc temporal comprès entre els segles II aC-V dC, així com les consideracions sobre la circulació monetària en aquest enclavament, i en general, a les comarques meridionals del País Valencià.

Paraules clau: Parc de les Nacions, vil·la romana, monedes, circulació monetària.

\section{Abstract:}

This paper presents the collection of coins discovered during the archaeological excavations in the Roman villa Parc de les Nacions (Alicante, Spain). We catalogue the coins dating from the 2 nd century $B C$ to the 5 th century $A D$, and we analyze the monetary circulation of this site and in the southern regions of the Valencian Community.

Key words: Parc de les Nacions, Roman villa, coins, monetary circulation.

Copyright: (C) 2016 Immaculada Garrigós. This is an open access paper distributed under the terms 
El següent treball forma part d'una recerca molt més extensa (Garrigós 2013a) que vam dur a terme al Centre Cultural Las Cigarreras, al departament de Patrimoni Cultural de l'Ajuntament d'Alacant ${ }^{1}$. Amb el present estudi volem donar continuïtat a la difusió detallada dels fons numismàtics d'època antiga del Museu de la ciutat d'Alacant (MUSA), tal i com vam fer recentment amb l'enclavament de la vil-la romana de Casa Ferrer I (Garrigós 2013b).

En aquest fons trobem 56 monedes de la vil-la de Parc de les Nacions exhumades a les intervencions realitzades durant les dècades dels anys 80 i 90 del passat segle, així com en el transcurs de les excavacions fetes entre els anys 2009 i 2011 que van aportar el gruix de les peces existents. Aquestes abasten un període que va des del s. II aC fins al s. XIX, encara que nosaltres sols incidirem en aquelles d'època antiga, però esmentarem les característiques de les peces més recents. Així doncs, convé subratllar l'existència d'una publicació on s'analitzaven els exemplars apareguts fins aquell moment (Abascal 1993). D’una altra banda -i com també ens va passar amb la vil-la de Casa Ferrer I- cal recordar que de Parc de les Nacions hi ha monedes dipositades al Museu Arqueològic Provincial d'Alacant (MARQ), en conseqüència no $s$ 'ha pogut aconseguir una visió completa del registre numismàtic de l'assentament, encara que se'ns va facilitar informació sobre el material que ha estat inclosa dins l'epígraf III. Confiem que en un futur pròxim es puga conèixer aquest de manera detallada.

\section{LA VIL·LA ROMANA DE PARC DE LES NACIONS}

L'assentament romà de Parc de les Nacions (figs. 1 i 2), al terme municipal d'Alacant, es troba situat a poc més de $300 \mathrm{~m}$ a l'E del Tossal de Manises-Lucentum i a 9,91 m s.n.m. a l'inici d'un suau vessant, en uns solars erms entre les vies de l'avinguda Esportista Míriam Blasco i els carrers Pallas Atena i Afrodita.

Es tracta d'un enclavament, amb una extensió aproximada d'uns $15.000 \mathrm{~m}^{2}$, que ha estat descrit com una vil.la i una necròpolis d'incineració. La primera abraça des del s. I aC fins a mitjan del VI dC, on es va plantejar anys enrere una adscripció altimperial per a la pars urbana i altra més tardana -finals s. IV i V dC- documentada sobretot a la zona rustica d'aquesta (Rosser et al. 1992). Segons anàlisis preliminars de Barahona i Molinos (2010) es va determinar l'existència de dos nivells d'ocupació: el primer d'època altimperial i el segon amb dues fases constructives que van del s. I al $V d C$. A la vil-la les estructures documentades són d'habitació de la part residencial (amb pintures i termes amb hipocaustum) però cal destacar també la pars rustica, on va aparèixer un forn, una almàssera o torcularium $\mathrm{i}$ un magatzem. Pel que fa a la necròpolis, amb una cronologia altimperial, aquesta sembla no perdurar en el temps i abraça una etapa molt concreta que correspon a la primera meitat del s. I dC. Segons Rosser (1990-1991: 93) entre els materials apareguts en ella hi havia una moneda d'August a la tomba 5 , informació que li va arribar mitjançant uns aficionats (ja que ell tampoc va poder veure la peça).

Les dades presentades descriuen breument el jaciment, que ha estat analitzat de manera més estesa en altres ocasions a les quals remetem (Rosser 1990, 1990-1991 i 1994; Ronda 1993; Olcina i Pérez 2003; Rosser et al. 1992 i 2007; Barahona i Molinos 2010; Frías 2010; Rosser i Molinos 2011; Molinos 2012). Tanmateix les publicacions existents gairebé esmenten contextos ja que es tracta d'aproximacions o presentacions provisionals dels materials que a més a més fan referència a intervencions dutes a terme els últims anys de la dècada dels 80 i inici de la dels 90 del segle passat (Rosser et al. 1992; Abascal 1993).

\section{INTERVENCIONS ARQUEOLÒGIQUES}

Les excavacions en aquest jaciment vénen realitzant-se des de la dècada dels anys 80 del passat segle, on a les primeres campanyes ja van aparèixer monedes (Abascal 1993). Actualment es comptabilitzen com hem esmentat anteriorment un total de 56 peces (fig. 3), que

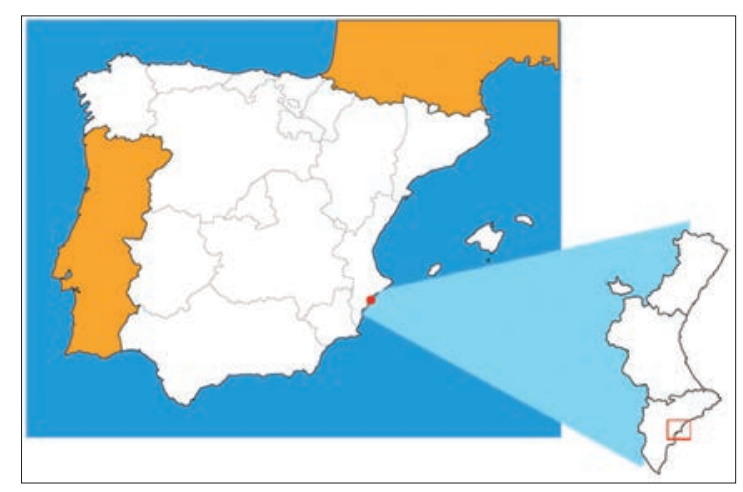

Fig. 1: Situació geogràfica de l'àmbit d'estudi. 


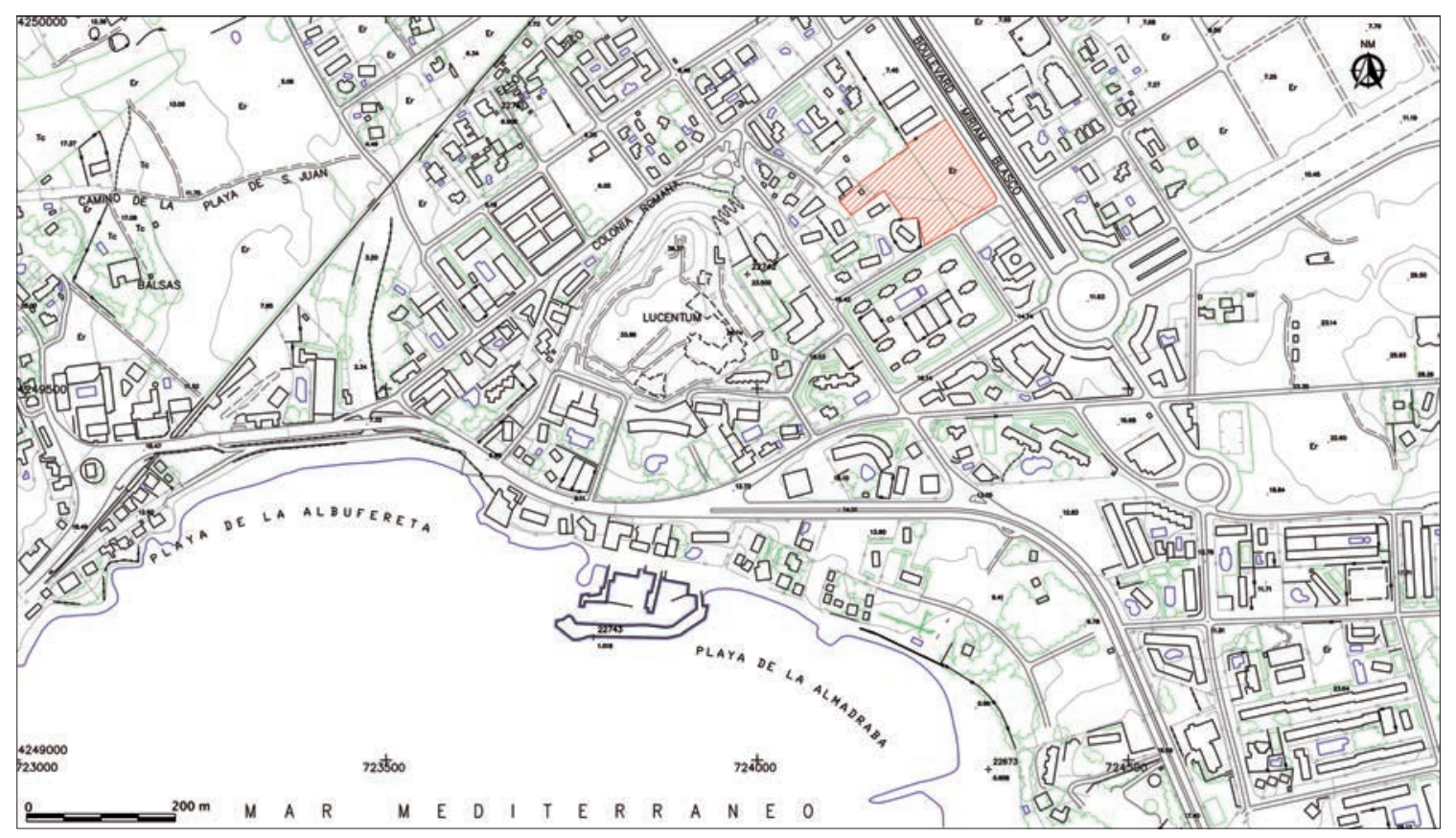

Fig. 2: Ubicació de l'enclavament (Font: Patrimoni Cultural).

han estat catalogades i revisades amb la intenció de proporcionar nova informació, no sols de l'assentament sinó també de la massa monetària de la zona.

Si analitzem les troballes de les campanyes realitzades hem de dir que la de 1988 va proporcionar 13 exemplars, la de 1989 tres, en 1993 sols va aparèixer una moneda del Govern Provisional durant la neteja d'un pou, l'any 2009 va ser la campanya que més peces va donar amb un total de 27 , mentre que a la continuació d'aquesta en 2010 es van trobar 11. Convé destacar que hi ha un semis de la seca d'Ebusus que no sabem a quina campanya pertany ni tenim informació sobre el lloc on va aparèixer.

Dels 13 exemplars de l'any 1988 destaquem l'as de Domicià, l'antoninià de Gal-liè, el follis de les Sèries Urbanes, els tres nummi de Constanci II i el d'atribució dubtosa entre Constanci II i Julià, el nummus de Gracià i les cinc peces d'atribució indeterminada. De 1989 sols comptem amb tres monedes: un as de Claudi amb Minerva al revers i dos antoninians, un de Gal-liè amb el revers de Providentia i l'altre pòstum de Claudi II amb llegenda Consecratio. Cal recordar la publicació realitzada en 1990 (Rosser 1990: 193) on trobem que l'any 1987 es va excavar a la zona -Llobregat i Uroz- i segons fonts orals d'un dels arqueòlegs van aparèixer monedes baiximperials. Igualment se'ns parla que durant les intervencions dutes a terme en 1988-1989 van trobar-se peces de Trajà, Gal-liè i Claudi II, mentre que al nivell de destrucció de la cellae olearia van aparèixer també de Constantí II i Gracià, i en altres parts de la vil-la es descobriren més exemplars, entre els quals destaca un de les Sèries Urbanes (Rosser 1990: 204 i 206-207). Les peces esmentades, excepte la de Trajà que es troba al MARQ, pertanyen als fons del MUSA.

Durant la campanya efectuada entre 2009-2010 es va excavar als sectors A i B (fig. 4), on va aparèixer material numismàtic a diferents estrats com seguidament detallem. Al sector A1 trobem peces a les UUEE 1076, 1101, 1129 i 1175; al sector A2 trobem a la UE 1203 interpretada com a rebliment, una possible xapa $\mathrm{i}$ un as de Tiberi emès a Turiaso; a l'A3 UE 1000 trobem una moneda de 5 cèntims del Govern Provisional encunyada el 1870 que correspon al tipus 10, núm. 25 de Calicó (2008: 809) i a la UM 1222, que ha estat interpretada com un paviment molt deteriorat, un as de Claudi; al sector A4 UE 1158 (rebliment) una moneda d'August encunyada a Carthago Noua mentre que al sector A6 UE 1071 un bronze de Tiberi de la mateixa seca, així mateix existeix una peça que no ha pogut ser catalogada pel seu mal estat de conservació. 


\begin{tabular}{|c|c|c|c|c|}
\hline & Seques & Total & $\%$ & $\%$ Total \\
\hline Segles II-I aC & & & & 3,56 \\
\hline Fenopúnica & Ebusus & 1 & 1,78 & \\
\hline Indígena & Indeterminada & 1 & 1,78 & \\
\hline Segles I-II dC & & & & 21,39 \\
\hline August (27 aC $-14 \mathrm{dC})$ & Carthago Nova & 1 & 1,78 & \\
\hline \multirow[t]{3}{*}{ Tiberi $(14-37 \mathrm{dC})$} & Carthago Nova & 1 & 1,78 & \\
\hline & Ilici & 1 & 1,78 & \\
\hline & Turiasu & 1 & 1,78 & \\
\hline Calígula $(37-41 \mathrm{dC})$ & Carthago Nova & 1 & 1,78 & \\
\hline \multirow[t]{2}{*}{ Claudi (41-54 dC) } & Roma & 1 & 1,78 & \\
\hline & Roma o seca local & 2 & 3,57 & \\
\hline Domicià (81-96 dC) & Roma & 1 & 1,78 & \\
\hline Atribució indeterminada & Indeterminada & 3 & 5,36 & \\
\hline Segle III dC & & & & 7,14 \\
\hline Gal-liè $(253-268 \mathrm{dC})$ & Roma & 3 & 5,36 & \\
\hline Claudi II (268-270 dC) & Roma o seca local & 1 & 1,78 & \\
\hline Segle IV dC & & & & 51,74 \\
\hline Sèries urbanes ( $1 \mathrm{r}$ període) & Thessalonica & 1 & 1,78 & \\
\hline Constantí II (337-340 dC) & Arelate & 1 & 1,78 & \\
\hline \multirow[t]{2}{*}{ Constant $(337-350 \mathrm{dC})$} & Cyzicus & 2 & 3,57 & \\
\hline & Roma & 1 & 1,78 & \\
\hline \multirow[t]{5}{*}{ Constanci II $(337-361 \mathrm{dC})$} & Arelate & 1 & 1,78 & \\
\hline & Constantinopolis & 1 & 1,78 & \\
\hline & Arelate o Constantinopolis & 1 & 1,78 & \\
\hline & Roma & 2 & 3,57 & \\
\hline & Indeterminada & 2 & 3,57 & \\
\hline Constanci II o Julià (337-363 dC) & Indeterminada & 2 & 3,57 & \\
\hline Constanci I, Constantí I o Constanci II & Indeterminada & 1 & 1,78 & \\
\hline Atrib. indet.: tipus gloria exercitus & Indeterminada & 3 & 5,36 & \\
\hline Atrib. indet.: tipus genet caigut & Indeterminada & 3 & 5,36 & \\
\hline Gracià $(375-383 \mathrm{dC})$ & Arelate & 1 & 1,78 & \\
\hline Atrib. indet.: altres tipus & Indeterminada & 7 & 12,5 & \\
\hline Indeterminades ss. I-V dC & Indeterminada & 6 & 10,72 & 10,72 \\
\hline Moderna-Contemporània & & & & 5,35 \\
\hline Diner s. XVII & València & 1 & 1,78 & \\
\hline Govern Provisional (1870) & Barcelona & 2 & 1,78 & \\
\hline TOTAL & & 56 & 100 & 100 \\
\hline
\end{tabular}

Fig. 3: Quadre-resum general de les troballes.

$\mathrm{Al}$ sector B es va documentar una estança pavimentada amb opus signinum d'on es van extraure fusts d'unes columnes, un capitell i nombrosos fragments d'estuc pintat (Barahona i Molinos 2010). En aquest sector ens trobem amb altres materials entre els quals volem destacar les monedes aparegudes al B1: a la UE 1019 un nummus d'atribució indeterminada, a la 1031 un de Constanci II, a la UE 1037 un altre de Constanci II o Julià, a la UE 1157 un nummus de Constantí II encunyat a Arle; al sector B2 trobem monedes a dues UUEE, en aquest cas a la 1031 una peça de Tiberi encunyada a Ilici que es troba en mal estat i un nummus de Constant encunyat a Cízic, per altra banda a la 1036 hi ha dos nummi, un d'ells de Constanci II i l'altre amb dubtes entre aquest emperador o altres de la seua mateixa dinastia; al sector B3 UE 1184 (rebliment) trobem una peça de Constanci II; al sector B4 UE 1038 es van trobar tres nummi possiblement del s. IV dC i al B5 UE 1096 (rebliment) una moneda indeterminada que podria pertànyer als ss. IV-V dC.

Hi ha altres materials que apareixen a la zona $\mathrm{D}$, com una moneda que podria ser ibèrica. A la UE 1089 (ignorem el sector) trobem un exemplar de Constant encunyat a Cízic. Hi ha dues peces més de les quals desconeixem la UE i que es tractarien de nummi del s. IV dC, un d'ells de Constanci II. 


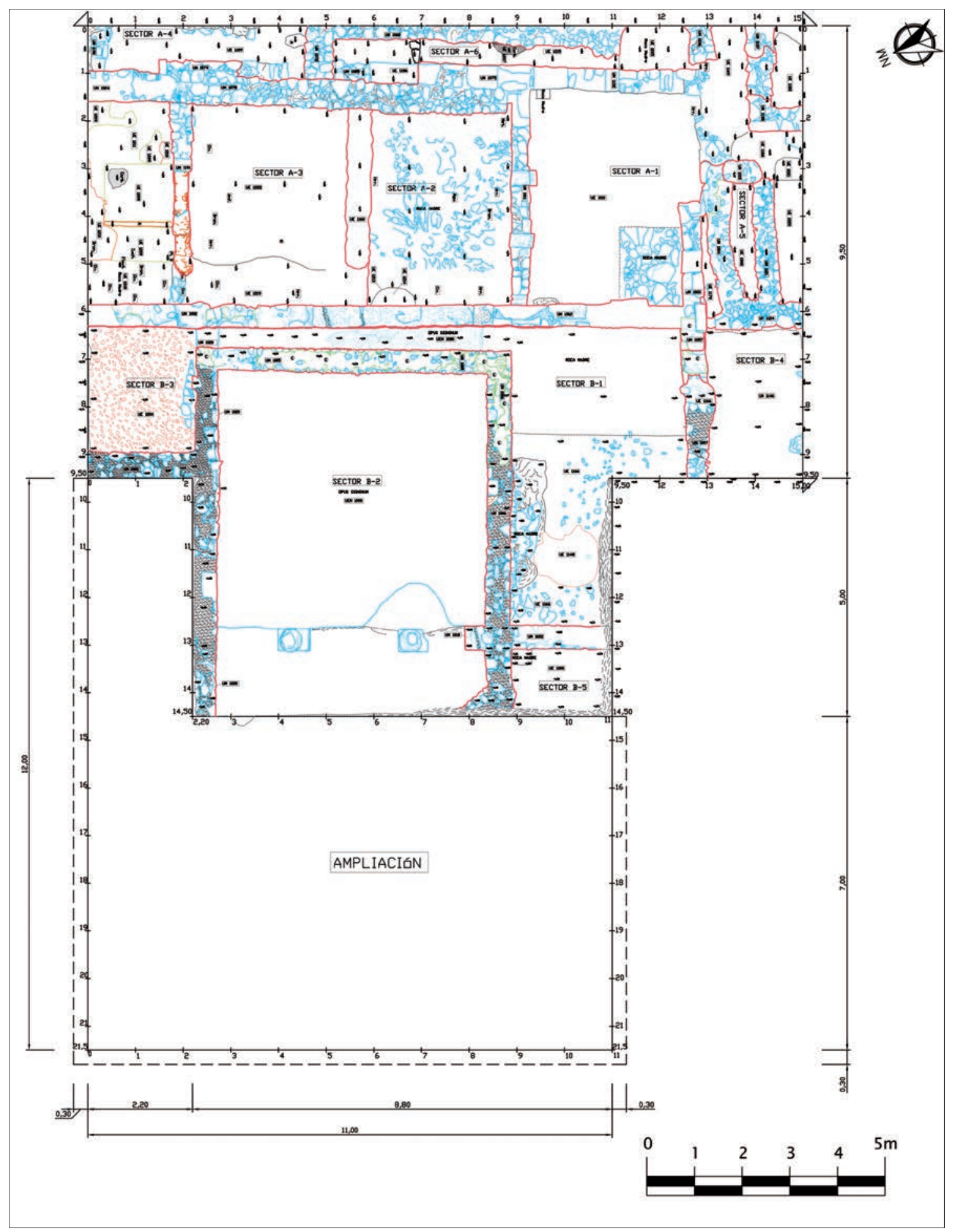

Fig. 4: Plànol excavació 2009-2010 (Font: Patrimoni Cultural). 


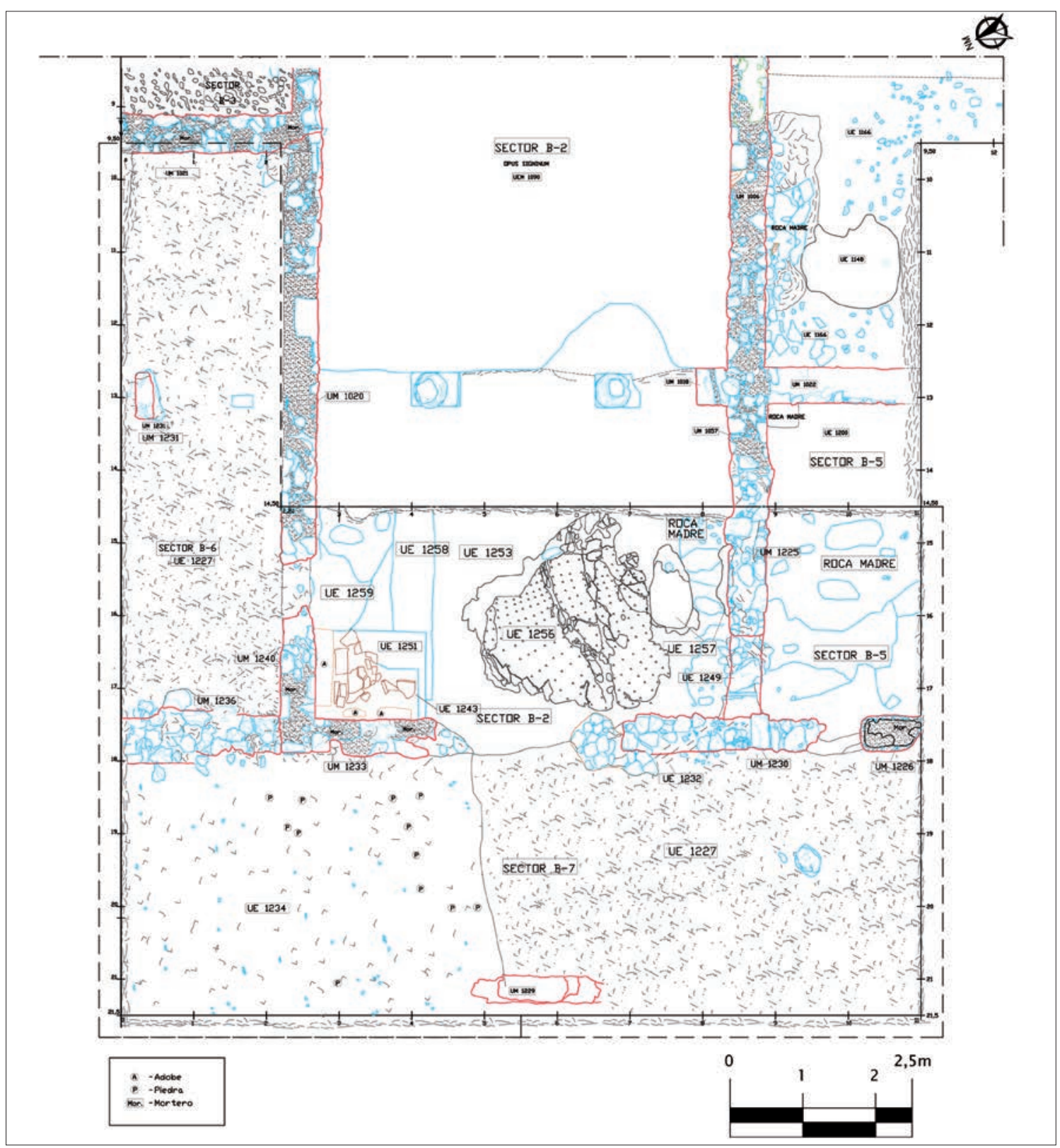

Fig. 5: Plànol excavació 2010-2011 (Font: Patrimoni Cultural).

La campanya d'excavació realitzada entre 2010-2011 (fig. 5) va aportar al conjunt monetari 11 exemplars més. En total els arqueòlegs en computen 12 però un cop nets $s$ 'ha descobert que un què havia estat identificat com a moneda és en realitat un botó. Segons l'informe preliminar de l'excavació van aparèixer dues petites peces al sector B2, UE 1000 (estrat superficial), una de les quals un diner encunyat a València al s. XVII i l'altre un botó de bronze. En aquest mateix sector, però a la UE 1242 van aparèixer quatre monedes: un nummus del s. IV dC i la resta indeterminades. L'estrat format per terra molt dura i seca amb abundants restes de calç, arrebossat i fragments d'adobs, ha estat interpretat pels arqueòlegs com un nivell de rebliment $\mathrm{i}$ abandó. 
Al sector B5, la UM 1225 es tracta d'un mur amb una orientació E-O que es troba sobre la roca mare, que ha estat explicat com el perllongament de la UM 1006 i 1032 que no arriba a adossar-se a la UM 1230. Els materials trobats al nivell de la seua base suggereixen un possible origen en el s. I dC, però en fer-se la neteja de l'estructura va aparèixer un nummus del s. IV dC. Mentre que a la UE 1246 (estrat amb restes de carbó, estuc i calç) es van trobar dos nummi d'atribució indeterminada encunyats al s. IV dC amb fragments de vidre, metalls (ganivet de ferro) i tessel·les de color, que s'ha interpretat com a restes d'una foguera i nivell d'abandó. Continuant al mateix sector però a la UE 1250 , aquest estrat va ser explicat com una foguera on van aparèixer tessel-les de colors i tres monedes, de les quals una és indeterminada i podria pertànyer als ss. I o II dC, mentre que les altres, encunyades totes dues a Roma, són de Gal-liè i Constant.

\section{ANÀLISI I CIRCULACIÓ DE LA MASSA MONE- TÀRIA (fig. 6)}

\section{ENCUNYACIONS FENOPÚNIQUES}

Ybshm/Ebusus (Eivissa) va assolir el seu gran apogeu cap als ss. V-IV aC. Arran d'això, aquesta colònia púnica començà a emetre moneda segons recents estudis de Campo durant la primera meitat del s. IV aC (2013a: 61-62; 2013b: 12; 2014: 139) mentre altres autors van proposar l'últim terç del s. IV aC (Aranegui et al. 1993). Tot i així va ser, de totes les seques fenopúniques, la única que ho va fer fins a època de Claudi -encara que amb intermitències(Alfaro 1997: 64; Campo 2013a: 71). Aquestes monedes, que havien estat inicialment encunyades per a satisfer necessitats gairebé d'ús local, limitant la seua funció a situacions i pagaments quotidians i no a transaccions de gran volum, com apunta Campo -atés que aquestes continuarien pagant-se amb metall a pes, intercanvi de productes o bé altres formes de diner- també s'han trobat a la costa NE i llevant de la península Ibèrica i fins i tot al $\mathrm{S}$ de la Itàlica (2014: 143-144). L'àrea de difusió de les primeres emissions en bronze de la seca estarien relacionades amb la distribució de les àmfores púnico-ebusitanes i associades al comerç del vi així com a la importància del port de l'illa (Campo 2014: 143). L'exigua troballa d'aquestes peces als enclavaments sembla que té més a veure amb la baixa qualitat del metall i ser de petit mòdul -fet que ocasionaria problemes tant a l'hora de recuperar-les durant les excavacions com d'identificar-les i classificar-les- que no pas a la seua difusió que seria més forta (Campo 2013a: 62-63). Així doncs, s'han trobat exemplars a la costa alacantina com el de la villa de Parc de les Nacions on hi ha un semis (núm. 1) que correspon al grup XIX, període III de M. Campo (1976: 45-48), que proposa per a la peça una cronologia posterior al $91 \mathrm{aC}$ i anterior al $27 \mathrm{aC}$, i esmenta l'aparició del tipus a la neàpolis d'Empúries en estrats

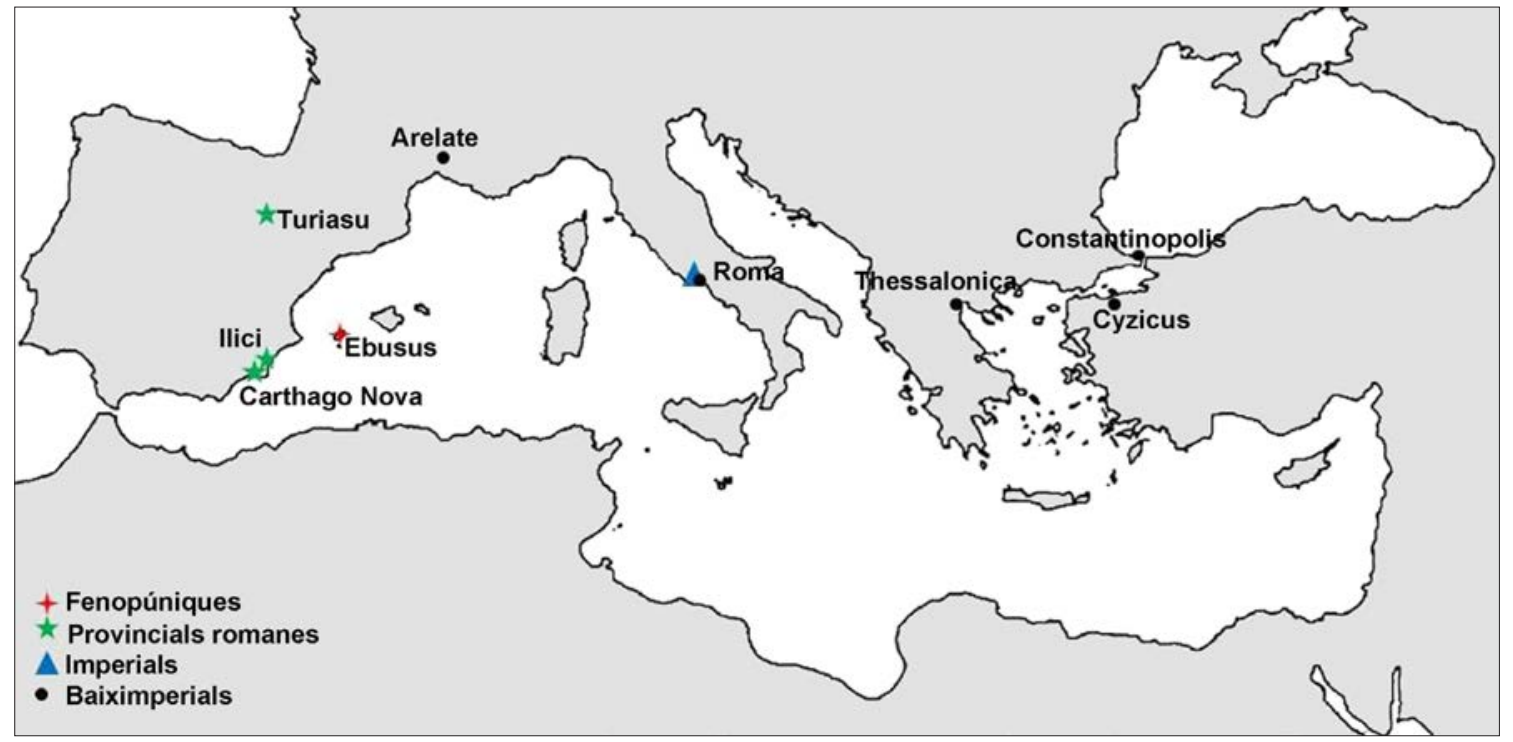

Fig. 6: Mapa de seques per períodes. 
d'abandó que corresponen a època flàvia, presentant graus de desgast molt lleugers (Campo 1993: 157), mentre que Villaronga (1994: 98) la situa a finals del s. II aC. En el cas del nostre bronze no podem saber amb quins materials va aparèixer al trobar-se descontextualitzat. La troballa d'exemplars púnics o emissions hispano-cartagineses a les comarques alacantines (Llobregat 1972; Ripollès 1980, 1982 i 2010; Arroyo i Bolufer 1988; Ramón 2002 i 2010; Garrigós i Mellado 2004; Abascal i Alberola 2007; Verdú 2010; Campo 2013a; Garrigós 2013a i 2013b) demostren com la circulació monetària durant l'últim quart del s. III $\mathrm{aC}$ quedava dins una òrbita netament púnica (Ripollès 1982: 267 i 274)

\section{EMISSIONS INDÍGENES}

L'aprovisionament irregular de moneda de bronze republicana a la zona i la demanda creixent d'aquesta -atesa l'activitat econòmica i comercial del territori, però també l'exèrcit i el desplaçament de les tropes per la península durant moments de conflicte-, va fer indispensables les encunyacions ibèriques tant per a cobrir els menesters d'ús local com per al finançament dels exèrcits o el pagament d'impostos (Campo 1999). En una de les últimes campanyes d'excavació realitzades a la vil·la va aparèixer un as (núm. 2) en mal estat de conservació, motiu pel qual ha estat impossible concretar el lloc d'encunyació i la cronologia ja que és molt difícil posar en clar cap iconografia, encara que pensem que podria pertànyer a finals del s. II i principis del I aC.

Així mateix, es coneixen monedes ibèriques en assentaments pròxims a Parc de les Nacions com els de la ciutat iberoromana de Lucentum (García et al. 2010: 354; Ramón et al. 2010: 102) o els de la vil·la de Casa Ferrer I (Garrigós 2013b), com també a la resta de comarques meridionals valencianes, tant costaneres com d'interior (Visedo 1959; Llobregat 1972; Ripollès 1980, 1982, 2007 i 2010; Abascal 1989; Alberola i Abascal 1998; Abascal i Alberola 2007; Mellado i Garrigós 2008; Garrigós i Santos-Olmo 2015), on cal recordar la important presència de peces batudes a les seques de Saitabi i Castulo.

\section{ENCUNYACIONS PROVINCIALS ROMANES}

Aquestes emissions cíviques van existir fonamentalment gràcies a la voluntat de colònies i municipis, $\mathrm{i}$ van facilitar el bon funcionament de l'economia de l'Imperi (Ripollès 1997: 383-385). Tanmateix, les seues encunyacions van ser irregulars i el seu àmbit de circulació local, fet lògic per ser monedes de bronze i tenir poc valor facial (Llorens 2002: 65). A la vil·la trobem una peça d'August, tres del seu successor i una de Calígula, mentre que les seques representades són tres: Carthago Noua (Cartagena), Ilici (l'Alcúdia, Elx) i Turiaso (Tarassona), amb un clar predomini de la primera, que va encunyar moneda cartaginesa per a cobrir part de les despeses de la segona guerra Púnica i que un cop sota domini romà, va deixar d'emetre fins a mitjan s. I aC. De la mateixa manera que van sorgir aquestes emissions, van deixar de realitzar-se en el regnat de Calígula, amb l'excepció de la seca d'Ebusus. Ripollès (1997: 395) ja va plantejar una sèrie de motius pels quals es deixa d'encunyar moneda i apunta que el que té més força, no és un altre que el de tipus polític.

L'as d'August presenta una perforació i va ser encunyat a Carthago Noua (núm. 3). Segons Llorens (2002: 52) els símbols que apareixen havien d'estar relacionats amb els càrrecs sacerdotals de la ciutat més que no pas amb els títols sacerdotals d'August. L'exemplar correspondria segons la investigadora a la XII emissió de la seca de Carthago Noua (Llorens 1994: 145), presentant la peça alguns problemes com el de precisar la data d'encunyació. Tanmateix Abascal va proposar fa uns anys una nova cronologia per a l'emissió que la situa cap a l'any $4 \mathrm{aC}$ (Abascal 2002: 31; Llorens 2002: 69) que ha estat acceptada pels investigadors. D'aquesta mateixa seca n'hi ha dues monedes més, una de Tiberi i altra de Calígula. Del successor d'August trobem un semis del tipus cap de Minerva galejat (núm. 5) que ha estat considerat durant molt de temps una emissió preaugustal (Llorens 2002: 51 i 72) pel seu caràcter anònim i per recordar la iconografia als denaris de l'any $42 \mathrm{aC}$ (RRC 494/38). Per contra Abascal aconsella modificar la datació de l'exemplar i situar-lo en l'any $17 \mathrm{dC}$ (2002: 24). Aquest replantejament ve donat pel canvi de denominació en el nom de la ciutat, ja que no va ser fins a inicis del regnat de Tiberi quan va adoptar oficialment el seu nou nom de Colonia Vrbs Iulia Noua Carthago sobre monedes $\mathrm{i}$ altres suports. Per a finalitzar amb aquesta seca cal esmentar l'as de Calígula (núm. 7) aparegut a les recents excavacions de la vil·la i encunyat cap a l'any 37 dC, peça que correspon a l'emissió XIX de Llorens (1994).

La colònia d'Ilici, Colonia Iulia Ilici Augusta -fundada aproximadament cap a l'any $42 \mathrm{aC}$, encara que fins al $26 \mathrm{aC}$ no se li afegeix l'últim epítet-, va començar a 
batre moneda per la necessitat dels nous colons assentats en ella, però no va ser suficient per a cobrir els menesters locals, fet que explica que la massa monetària predominant al territori fins a època de Tiberi siga la realitzada a Carthago Noua (Abascal 2004: 80 i 91-92). De les sis emissions encunyades per la seca d'Ilici, les tres últimes (4a, 5a i 6a) es van realitzar sota Tiberi, i van emetre de manera simultània asos i semis, mentre que les tres primeres ho van fer sols de semis durant època d'August. D'aquesta seca hi ha un as molt deteriorat de la 6a emissió (núm. 6) on a la llegenda del revers hi són les inicials de la colònia i els noms dels magistrats locals acompanyats de dues figures togades que es donen la mà sobre un altar, a sota del qual trobem la paraula iunctio. Les figures (RPC 198) han estat interpretades pels investigadors de diferents maneres, per a uns representarien Germànic i Drus -Grant i Etienne- i per a altres -Beltrán i Llorens- Tiberi i Sejà, encara que hi ha altres propostes per a les imatges com són: Neró i Drus o Tiberi i Calígula (Burnet et al. 1992: 98). L'associació als fills de Tiberi, Germànic i Drus, avançaria l'emissió a abans del $19 \mathrm{dC}$, però aquesta cronologia no convenç els autors del RPC.

El municipi de Turiaso (Tarassona, Saragossa) situat a la vall de l'Ebre va començar a batre moneda a mitjan s. II aC fins aproximadament finals del conflicte sertorià, i va continuar les emissions fins a època imperial amb el nom esmentat (Gozalbes 2009: 1). Les peces encunyades sota el regnat de Tiberi presenten algun problema a l'hora d'identificar les emissions, ja que cada magistratura era l'encarregada d'emetre un tipus, els duouiri batien els asos mentre que els aedili ho feien amb els semis (Burnet et al. 1992: 130). Amb un as de Tiberi (núm. 4) aparegut a la vil·la l'any 2009 en un estrat de rebliment tanquem l'apartat de seques hispanollatines, no sense esmentar abans les troballes d'emissions cíviques en assentaments pròxims a Parc de les Nacions, com els casos de Lucentum i la necròpolis de l'Albufereta (Ramón 2009 i 2010; Verdú 2010) o la villa de Casa Ferrer I (Garrigós 2013b), però també a les comarques meridionals del País Valencià on hi ha una preeminència de la seca de Carthago Noua, seguida per la d'Ilici i les seques de la vall de l'Ebre als diferents jaciments consultats (Ripollès 1980 i 1982; Arroyo i Bolufer 1988; Abascal 1989; Abascal i Gisbert 19901991; Alberola i Abascal 1998; Garrigós i Mellado 2004; Frías i Llidó 2005; Abascal i Alberola 2007; Abascal et al. 2007; Garrigós i Santos-Olmo 2015).

\section{MONEDES ROMANES}

\section{ELS SEGLES I I II DC}

Del regnat de Claudi comptem amb un dupondi i dos asos. La primera peça (núm. 8) és una encunyació realitzada a Roma, les altres són dos asos (núms. 9 i 10) del tipus Minerva que podrien haver-s'hi encunyat a la seca de Roma o bé a seques locals, encara que en el nostre cas pensem que es tracta de la segona opció. Quan les emissions cíviques van deixar d'encunyar-s'hi a Hispània durant el regnat de Calígula, el buit no va ser cobert per les imperials, fet que va dificultar el desenvolupament normal de la vida quotidiana a les ciutats. Aquest podria ser un dels motius pels quals sota el regnat de Claudi es van realitzar imitacions de monedes de bronze a tallers no oficials (Ripollès 1997: 390). Aquests exemplars, qualificats d'imitacions, es van beneficiar de llibertat de circulació arribant a assolir una àmplia difusió amb la intenció d'esmenar la mancança de numerari de bronze en aquell moment.

L'any 68 es produirà una guerra civil que desembocarà en l'arribada al poder de la dinastia flàvia. D'aquest període, malgrat l'escassetat de moneda trobada a la península, comptem amb un as de Domicià de l'any $86 \mathrm{dC}$ (núm. 11). Lledó (2010: 32-33) sosté que si l'època flàvia va ser un moment pròsper per a l'economia resulta contradictòria la seua insignificança dins la massa monetària, que ha estat explicada per la brevetat del període i la reducció de les emissions durant aquest. A més a més, també planteja que l'estabilitat d'aquells anys redueix considerablement els estrats d'abandó i destrucció on solen aparèixer les troballes, cosa a la qual s'ha d'afegir el volum de peces d'etapes anteriors que continuarien en circulació durant aquell temps. Cal recordar, com hem comentat anteriorment, que per al s. II dC sols tenim constància d'un sesterci de Trajà (Rosser 1990; Abascal 1993) dipositat al MARQ.

Pel que fa a monedes d'atribució indeterminada dels ss. I-II dC, comptem amb quatre asos que podríem adscriure a aquestes centúries. A la primera peça (núm. 12) el nivell de desgast és elevadíssim, fet que ens deixa intuir tan sols part de la iconografia a l'anvers -de factura molt tosca- mentre al revers s'aprecia una $\mathrm{C}$ al camp que formaria part d'una llegenda probablement amb S-C. A una altra d'elles pot veure's també la lletra $\mathrm{C}$, però totes dues cares són il·legibles (núm. 13); a la peça núm. 14, també il-legible, almenys es pot veure un cap a la dreta. La moneda 48 és totalment frustra per les dues cares, no obstant això, al tractar-se d'un as pensem que podria correspondre a aquest moment. 
Quant a emissions oficials, els ritmes d'alimentació monetària sobretot per a la segona meitat del s. I i per al s. II dC són irregulars, tanmateix per a les comarques alacantines es té constància d'exemplars a diferents enclavaments als quals remetem (Ripollès 1980; Arroyo i Bolufer 1988; Abascal 1989; Abascal i Gisbert 1990-1991; Alberola i Abascal 1998; Frías i Llidó 2005; Abascal et al. 2007; Abascal i Alberola 2007 i 2010; Ramón 2010; Garrigós 2013a i 2013b; Garrigós i Santos-Olmo 2015).

\section{EL SEGLE III DC}

D'aquesta centúria de grans transformacions i desequilibris a nivell monetari trobem quatre antoninians del període conegut com "anarquia militar" que pertanyen a Galliè i Claudi II. A partir del regnat del primer el volum de moneda apareguda als jaciments valencians augmenta considerablement per una inseguretat generalitzada, que accentua la presència de peces de tots dos emperadors en la massa monetària circulant a la península durant aquell moment fins al començament del següent segle (Lledó 2010: 36). L'increment és producte d'una intensificació en el volum d'emissió, així com d'un manteniment en circulació de determinats tipus monetaris. La inflació monetària a partir del regnat de Gal-liè en solitari (260-268 dC) és elevada i repercuteix greument sobre l'economia (Arroyo 1982). L'augment d'aquest tipus d'exemplars en circulació i per tant la major presència a diferents enclavaments de les comarques meridionals valencianes s'ha pogut constatar a les intervencions i troballes realitzades durant les últimes dècades a les quals remetem (Ripollès 1980; González i Abascal 1987; Arroyo i Bolufer 1988; Abascal 1989; Abascal i Gisbert 1990-1991; Alberola i Abascal 1998; Garrigós i Mellado 2004; Hurtado 2006; Abascal i Alberola 2007; Abascal et al. 2007; Lledó 2010; Garrigós 2013a i 2013b; Garrigós i Santos-Olmo 2015).

A la vil·la van aparèixer -a diferents campanyes d'excavació- quatre antoninians, tres dels quals són de l'emperador Gal-liè encunyats a Roma i un de Claudi II el Gòtic. En el cas dels tres primers, un d'ells es va realitzar els anys 255-256 dC (núm. 15). Les altres dues monedes (núms. 16 i 17) van ser encunyades entre el 259-268 dC i són còpies del mateix tipus amb llegenda al revers FORTVNA REDVX. El regnat de Claudi II va ser breu (268-270 dC), tot i així comptem amb un antoninià encunyat després del $270 \mathrm{dC}$ a Roma o a seca local, amb DIVO CLAVDIO a l'anvers, tipus d'emissió pòstuma, realitzada generalment per tallers locals, que va ser molt comú a Occident.

\section{ELS SEGLES IV I V DC}

Del material estudiat el s. IV dC és el més representat amb 33 exemplars que constitueixen el 58,93\%, mentre que hi ha una moneda indeterminada que podria correspondre als ss. IV o V dC. Les peces de bronze o nummi d'aquests segles generalment es troben en mal estat de conservació o bé molt desgastades a causa de la seua residualitat monetària.

Entre les seques representades a l'assentament trobem de les dues zones de l'Imperi, destacant en nombre les orientals, però no la quantitat de peces atribuïdes a aquestes. Els llocs identificats no han estat massa elevats, encara que hem reconegut tres monedes d'Arelate (Arle) i el mateix nombre de la de Roma, això ens mostra que els sis exemplars adscrits a les dues seques occidentals representen el 54,55\% de les monedes amb lloc d'encunyació identificat. Per contrast s'han registrat tres seques orientals: Tessalònica i Constantinoble amb una peça cadascuna, i Cízic amb dues, el 36,36\% d'exemplars amb procedència coneguda. Tanmateix, el gruix de nummi apareguts dels quals no ha estat possible identificar el lloc d'encunyació representa el 67,65\% de 34 monedes, fet que palesa el baix percentatge de peces amb seca adscrita.

Dels exemplars existents sols en disposem d'un corresponent al primer període de les Sèries Urbanes encunyat a Tessalònica entre el 330 i 333 dC (núm. 19). De Constantí II trobem una peça encunyada a Arle entre els anys 336-337 dC (núm. 20) del tipus gloria exercitus amb un estendard i pensem que correspon a aquesta ciutat perquè el $328 \mathrm{dC}$ Arelate va ser rebatejada -en honor a Constantí II- amb el nom de Constantina, pel que la marca a les monedes amb què es va identificar en aquell moment va ser: KONSA, PCON o PCONS (Royo 2009: 167). Altrament de Constant trobem tres monedes d'un mateix moment que representen el tipus gloria exercitus, dues de les quals encunyades a la seca de Cízic i altra a la de Roma. Les tres, però, tenen llegendes molt diferents a l'anvers. En el cas de les dues encunyades a la seca oriental, encara que la llegenda del revers siga gloria exercitus, una té un estendard i l'altra dos. Aquesta última (núm. 21) amb una cronologia que oscil·la entre 331 o 333-334 dC du llegenda a l'anvers FL IVL CONSTANS NOB C; per altra banda, la que du un sol estendard és de l'any 340 dC (núm. 22), ja com a emperador. De Constant també és el nummus del mateix any $i$ tipus, però amb un estendard, encunyat aquesta vegada a Roma (núm. 23). 
Constanci II és dels tres fills de Constantí el millor representat, ja que comptem amb 7 exemplars d'adscripció segura entre els materials estudiats. Trobem bronzes dels tipus tant de soldat que llanceja a genet caigut com de Spes, on hi predomina el primer amb sis peces de diferents seques. Del conegut com a falling horseman hi ha un nummus batut a Constantinoble entre el 351-355 dC (núm. 24), d'on també podria haver eixit la peça núm. 25, encara que tenim dubtes respecte a l'encunyació ja que podria haver-s'hi realitzat igualment a Arle. El seu desgast ha impossibilitat desxifrar totes les lletres de l'exerg on es troba la informació sobre la seca, per aquest motiu ha estat adscrita al període durant el qual es va encunyar aquest tipus. De la de Roma trobem dos nummi de genet caigut, un d'ells encunyat entre els anys 352-355 dC (núm. 26) i l'altre del 355-361 dC (núm. 27). D’aquesta dècada i poc més, són les dues monedes amb llegenda a l'anvers D N CONSTANTIVS P F AVG (núm. 28-29) de les quals no hem pogut identificar la seca però sí associar-les, gràcies a la llegenda i la iconografia, al tipus del que fins ara hem estat tractant. Les monedes del tipus FEL TEMP REPARATIO (Felix Temporum Reparatio) amb genet caigut al revers, són de les més abundants durant el s. IV dC entre les trobades als enclavaments del País Valencià. La difusió d'aquests exemplars de Constanci II va començar a partir de l'any 350 , però dos anys abans la llegenda ja havia estat introduïda per a fer-la coincidir amb el 1100 aniversari de Roma (Sutherland i Carson 1981: 34-35). L'altre exemple que trobem d'aquest emperador al jaciment és un nummus del tipus Spes, encunyat a Arle entre els anys 355-360 dC (núm. 30).

D'atribució dubtosa entre Constanci II o Julià són els dos nummi del tipus Spes al revers encunyats entre 355363 dC (núms. 31-32). També n'hi ha un nummus de la primera meitat del s. IV dC (núm. 33) del qual no coneixem l'atribució precisa, ja que el revers és il-legible i a l'anvers sols es pot veure part de la llegenda CONSTAN, de manera que podria pertànyer a qualsevol dels primers membres de la dinastia constantiniana.

Quant a les peces d'atribució indeterminada però que hem pogut adscriure a algun tipus iconogràfic i per tant enquadrar-les en una cronologia concreta hem de dir que de la primera meitat de la centúria n'hi ha quatre monedes de les quals desconeixem l'atribució exacta a un emperador o fins i tot a alguna seca. Així doncs, de gloria exercitus trobem dos subtipus: el que du un estendard, encunyat majoritàriament entre els anys 335-340 dC, i el que presenta dos estendards realitzat entre el 333 i 334 dC.
D'aquest últim tipus trobem una peça (núm. 35) que hem associat a gloria exercitus malgrat no poder llegir la llegenda, però sí veure la iconografia del revers i que per algunes de les lletres de l'anvers podria tractar-se de Constantí. Com també n'hi ha dos nummi realitzats entre els anys 335-340 dC amb un estendard, dels quals desconeixem l'atribució i la seca (núms. 36-37). Altre tipus representat entre les monedes estudiades ha estat el de victoria augusti del qual tenim un possible exemplar, la cronologia del qual va del 337 al $351 \mathrm{dC}$ però desconeixem la seca $\mathrm{i}$ l'emperador (núm. 41). Pel que fa a la segona meitat d'aquest segle trobem una sèrie de peces encunyades entre 350-361 dC que corresponen a FEL TEMP REPARATIO amb soldat a l'esquerra que llanceja genet caigut. Es tracta del tipus més representat, no sols entre les monedes associades a un emperador i ja descrites abans, sinó entre les d'atribució indeterminada. D'aquestes comptem amb dos nummi (núms. 38-39). Hi ha un bronze (núm. 40) d'atribució indeterminada que pensem podria correspondre al tipus de genet caigut o bé al de gloria exercitus, però pel mal estat de conservació ha estat impossible poder-hi extraure més informació, no obstant això, la seua cronologia coincidiria amb la dels tipus esmentats. De l'últim quart del s. IV tenim un nummus de l'emperador Gracià (núm. 34) encunyat entre els anys 378 i $383 \mathrm{dC}$ a Arle.

Com es pot observar el s. IV dC és el millor representat a la vil-la (fig. 7), ja que les peces d'aquesta centúria són abundants. Una bona mostra del que hem exposat són els exemplars que s'han trobat en un nombre

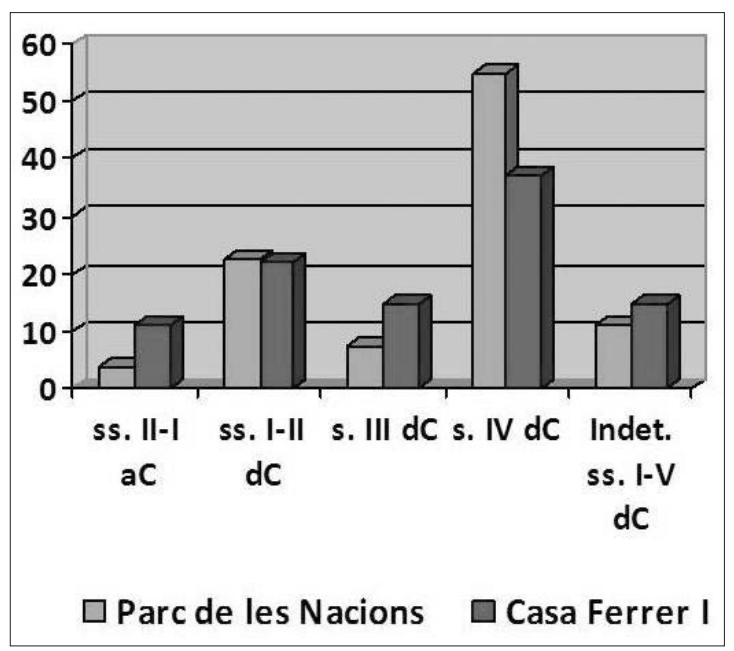

Fig. 7: Gràfic per períodes i comparativa de les troballes de les vil·les PN i CFI. 
destacat de jaciments, que no enumerarem però als quals remetem (Ripollès 1980; Arroyo 1985 i 1988; Arroyo i Bolufer 1988; Abascal 1989; Abascal i Gisbert 1990-1991; Alberola i Abascal 1998; Marot et al. 2000; Garrigós i Mellado 2004; Frías i Llidó 2005; Abascal i Alberola 2007 i 2010; Abascal et al. 2007; Lara et al. 2007; Ramón 2010; Garrigós 2013a i 2013b; Garrigós i Santos-Olmo 2015).

\section{MONEDES DELS SEGLES IV I V DC INDETERMI- NADES I NO CLASSIFICABLES}

A la villa de Parc de les Nacions trobem sis monedes adscrites als ss. IV i/o V dC però d'atribució indeterminada i seca desconeguda. En el cas de la peça 43 es pot veure a l'anvers un bust drapejat $i$ amb cuirassa a la dreta amb possible casc i al revers una figura togada que sosté amb les mans una bola o casc i la pròpia toga. N'hi ha tres nummi en els quals a l'anvers es pot veure bust o cap a la dreta i l'altra cara és il·legible (núms. 44, 45 i 47); la peça núm. 42 té a l'anvers la mateixa iconografia, a més a més de part d'una llegenda que tampoc ens proporciona la informació necessària per a adscriure-la a un emperador encara que podria correspondre a la primera meitat del s. IV, i a la moneda núm. 46 trobem bust a la dreta amb diadema de perles i drapejat, mentre que al revers una figura de peu. En canvi comptem amb cinc monedes no classificables o frustres (núms. 49-53) amb una cronologia que pensem oscil-la entre els ss. IV i V dC, no obstant això alguna d'elles podria pertànyer al s. VI dC. No descartem que algun exemplar siga vàndal, tanmateix i a causa del seu mal estat no podem saber-ho. Com bé va apuntar Marot (2000-2001: 134), la perdurabilitat d'aquestes peces és un fet habitual que juntament amb l'estudi d'altres materials que aporten cronologies, afavorirà un millor coneixement de la circulació monetària durant els ss. V i VI dC.

\section{CONCLUSIONS}

Entre les diferents vil-les suburbanes existents al voltant de la ciutat iberoromana de Lucentum-Tossal de Manises es va trobar, a pocs metres, la de Parc de les Nacions amb una ampla cronologia (ss. I aC - mitjan VI $\mathrm{dC}$ ). Les troballes numismàtiques exhumades -hem presentat 56 de les quals 53 pertanyen a època antigaens permeten conèixer un poc més la circulació monetària en aquest territori durant l'antiguitat. Les peces analitzades abracen un període que va del s. II aC fins al s. XIX, les tres més recents fruit d'alguna freqüentació esporàdica de la zona. Entre aquestes últimes cal destacar un diner encunyat a València el s. XVII i dos exemplars de 5 cèntims del Govern Provisional (Garrigós 2013a: 46).

En el cas d'aquesta vil-la suburbana ocorre el mateix que a l'assentament de Casa Ferrer I (Garrigós 2013 b) on no trobem monedes que no siguen de bronze i per tant destinades a l'adquisició o bescanvi de mercaderies modestes realitzades habitualment en circuits locals o pròxims als llocs d'emissió. Aquest fet no implica la inexistència d'exemplars batuts en altres metalls, i per tant la seua circulació a la zona, però sí la poca representació d'aquestes troballes al territori estudiat. Entre les peces cal destacar-ne les encunyades a la península, ja siguen aquestes fenopúniques com la d'Ebusus, ibèriques o també provincials. Predominen entre les emissions cíviques les realitzades sobretot a Carthago Noua, però també trobem exemplars d'Ilici i la zona de la vall de l'Ebre, com és el cas del municipi de Turiaso, tal i com s'ha documentat en altres enclavaments de les comarques meridionals valencianes. D'altra banda, cal esmentar en aquest cas la poca presència d'exemplars del s. I dC batuts a Roma i l'existència d'imitacions locals sota el regnat de Claudi, tan comuns a molts enclavaments durant aquesta centúria. Convé subratllar la quasi absència a l'assentament i fins al moment, de monedes del s. II dC -excepte l'existent al MARQ- que coincideix amb la tendència descendent dels ritmes d'aprovisionament per a aquest període (Arias 2006: 159-161).

Pel que fa al s. III dC trobem antoninians de Gal-liè i un de pòstum de Claudi II, peces habituals per a aquest moment i posteriors, com també els nummi del s. IV dC que prevalen al llarg d'aquesta centúria i les següents, fet demostrat pel desgast de les peces.

És important recordar, com bé apunta Molinos (2012), que no existeixen estudis íntegres publicats bé dels materials bé dels nivells on s'han trobat, per tant ni els informes preliminars ni les memòries afavoreixen una informació completa. Consegüentment, la manca d'aquests estudis dificulta la possibilitat d'assolir informació sobre els contextos arqueològics i no facilita l'oportunitat de conèixer la perdurabilitat de les monedes en circulació, de manera que no explica el desgast de les peces, especialment les dels ss. III i IV-V dC. 
Per concloure dir que el material numismàtic presentat aporta nova informació sobre els patrons d'abastiment monetari en l'ager de la ciutat de Lucentum, que coincideixen amb els de la resta de les comarques meridionals del País Valencià. És a dir un període amb poca presència de numerari durant el s. II dC, que poc té a veure amb l'evolució econòmica de l'Imperi, i una massa monetària destacada en etapes molt concretes com són la primera meitat del s. I dC amb les emissions cíviques i els ss. III i IV dC.

\section{CATÀLEG}

La configuració del catàleg segueix la mateixa línia d'altres estudis numismàtics. Les monedes estan ordenades cronològicament per emperador. El número indicat al principi de cada peça, ha estat assignat per nosaltres per a l'elaboració d'aquest estudi. Les referències que hi permeten la classificació apareixen en els casos on ha estat possible després de les dades relatives a pes, diàmetre $\mathrm{i}$ posició d'encuny, mentre que la indicació Bibl. seguida d'una cita revela si la moneda ha estat publicada prèviament $\mathrm{o}$ és inèdita.

1. EBUSUS. Semis. Post. $91 \mathrm{aC}-$ anterior $27 \mathrm{aC}$

A. Bes vestit amb faldilla, amb el cap amb un tocat de plomes, que sosté una maça i una serp; a esquerra lletres fenícies aleph i zayin.

R. Il-legible, però en dues línies ha d'haver-hi: en la superior llegenda fenícia 'YBSM, a la inferior marca de valor 50.

$5,9 \mathrm{~g} ; 22 \mathrm{~mm}$; -

CNH, Ebusus-61 o 62; Campo, Grup XIX, període III

Inv.: 3.442

Bibl.: Inèdita

PN'--

2.ATRIBUCIÓ INDETERMINADA.As. Seca? finals s. II - pp. s. I aC

A. Il-legible. Cap a la dreta.

R. [---] signes ibèrics ON. Il·legible.

$7,1 \mathrm{~g} ; 27 \mathrm{~mm}$; -

Inv.: 3.411

Bibl.: Inèdita

PN'09, zona D (?)

Observ.: un dels cantells trencat.

\author{
3. AUGUST. As. CARTHAGO NOVA. Ca. 4 aC \\ A. [augustus] - DIVI [f]. Cap llorejat d'August a la dreta. \\ R. C V[ar ruf] SE[x iul pol] II [vir q]. Atributs sacerdotals (simpu- \\ llum, aspergillum, securis i apex). \\ $12,8 \mathrm{~g} ; 29,5 \mathrm{~mm} ; 3 \mathrm{~h}$.
}

RPC 167; Vives, CXXXI, 10-11; Llorens, 1994, XIIA

Inv.: 3.404

Bibl.: Inèdita

PN'09, A4, UE 1158

Observ.: té perforació.

4. TIBERI. As. TURIASU. $14-37 \mathrm{dC}$

A. TI [ca]ESAR AVG F IMP PONT M. Cap llorejat a la dreta.

R. MVN·TVR/ M PONT MARSO / [c mar]I VEGETO / II VIR. Bou a la dreta.

$11,9 \mathrm{~g} ; 28 \mathrm{~mm} ; 9 \mathrm{~h}$

RPC 418; Vives, làm. CLVI, 11

Inv.: 3.405

Bibl.: Inèdita

PN'09, A2, UE 1203

5. TIBERI. Semis. CARTHAGO NOVA. Ca. $17 \mathrm{dC}$

A. Cap galejat de Minerva a la dreta.

R. [c v - i n]. Estàtua sobre pedestal.

$7,0 \mathrm{~g} ; 23,8 \mathrm{~mm} ; 4 \mathrm{~h}$ ?

RPC 151; Vives, làm. CXXX, 1; Llorens 1994, IV

Inv.: 3.406

Bibl.: Inèdita

PN'09, A6, UE 1071

Observ.: té enganxat un tros de bronze en el lateral a la zona de l'anvers.

6. TIBERI. As. 6a emissió, ILICI. 28-31 dC

A. [ti caesar divi au]G F AV[g pm]. Cap nu d'emperador a l'esquerra. R. [c i i a 1 ter lon 1 pap av]IT II VIR Q. Dues figures togades donant-se les mans sobre altar, sota: [iunctio].

$5,6 \mathrm{~g} ; 26,5 \mathrm{~mm} ; 2 \mathrm{~h}$.

RPC 198; Vives CXXXIII, 13; Llorens, 140-68

Inv.: 3.408

Bibl.: Inèdita

PN'09, B2, UE 1031

Observ.: està quartejada, prou deteriorada.

7. CAlígula. As. CARTHAGO NOVA. Ca. $37 \mathrm{dC}$

A. [c caesar aug germanic imp p m t]R P COS. Cap llorejat a la dreta. R. CN [atel flac en po]M FLAC II [vir] QVINC. Cap femení a la dreta, en camp: [sa]L - AV [g] a esquerra i dreta.

$15,3 \mathrm{~g} ; 28,9 \mathrm{~mm} ; 11 \mathrm{~h}$.

RPC 185; Vives, làm. CXXXII, 7-10; Llorens 1994, XIXa

Inv.: 3.409

Bibl.: Inèdita

PN'09, A1, UE 1175

8. CLAUDI. Dupondi. ROMA. 41-50 dC

A. [ti claudius cae]SAR AVG [p]M [tr p imp]. Cap nu d'emperador a l'esquerra.

R. [ceres - augusta]. Ceres tapada i drapada asseguda cap a l'esquerra 
en tron ornamental que sosté dues espigues en la mà dreta i du vara llarga en l'esquerra.

Exerg: [sc]

$14,0 \mathrm{~g} ; 27,2 \mathrm{~mm} ; 6 \mathrm{~h}$.

RIC I, 94

Inv.: 3.410

Bibl.: Inèdita

PN'09, sector A1, UE 1101

9. CLAUDI. As. ROMA o seca local. 41-50 dC

A. TI CLAV[diu]S CAES[ar aug p]M [tr p i]M[p]. Cap nu d'emperador a l'esquerra.

R. Minerva avançant cap a la dreta amb casc, en mà dreta du javelina i a l'esquerra escut rodó, als costats: $\mathrm{S}-\mathrm{C}$.

$11,8 \mathrm{~g} ; 30,5 \mathrm{~mm} ; 12 \mathrm{~h}$.

RIC I, 100

Inv.: 3.399

Bibl.: Abascal, 1993

PN'89, exc. capa sota mur estuc (1,15 prof.)

10. CLAUDI. As. ROMA o seca local. $41-50 \mathrm{dC}$

A. [ti claudius caesa]R AVG P[m tr p imp]. Cap nu d'emperador a l'esquerra.

R. Minerva avançant cap a la dreta amb casc, en mà dreta du javelina i a l'esquerra escut rodó, als costats: [s]-C.

$12,8 \mathrm{~g} ; 28,5 \mathrm{~mm} ; 7 \mathrm{~h}$

RIC I, 100

Inv.: 3.407

Bibl.: Inèdita

PN'09, A3, UM 1222

\section{DOMICIÀ. As. ROMA. $86 \mathrm{dC}$}

A. IMP CAES D[omi]T [aug] GERM COS X[ii cens per p p]. Bust llorejat de l'emperador a la dreta.

R. F[ortu]NAE [augusti], S-C. Fortuna de peu a esquerra, amb timó i cornucòpia.

$10,6 \mathrm{~g} ; 28 \mathrm{~mm} ; 6 \mathrm{~h}$

RIC II, 333

Inv.: 3.443

Bibl.: Inèdita

PN'88?, cala 11, UE 1004

12. ATRIBUCIÓ INDETERMINADA. As. Seca? s. I dC

A. Bust masculí a l'esquerra (?).

R. Il-legible.

$8,7 \mathrm{~g} ; 26 \mathrm{~mm} ; 6 \mathrm{~h}$.

Inv.: 3.444

Bibl.: Inèdita

PN'88?, cala 14, UE 4001

13. ATRIBUCIÓ INDETERMINADA. As. Seca? s. I dC

A. C[---]. Il-legible.

R. Il-legible.
$11,4 \mathrm{~g} ; 27 \mathrm{~mm}$; -

Inv.: 3.387

Bibl.: Inèdita

PN'88, cala 6, capa vegetal

14. ATRIBUCIÓ INDETERMINADA. As. Seca? ss. I-II dC

A. [---]. Cap a la dreta.

R. Il·legible.

$13,3 \mathrm{~g} ; 25,8 \mathrm{~mm} ;-$

Inv.: 3.431

Bibl.: Inèdita

PN'10, B5, UE 1250

15. GAL·LIÈ. Antoninià. ROMA. 255-256 dC

A. IMP C P LIC [g]ALLIENVS P[f a]V[g]. Bust radiat i amb cuirassa a la dreta.

R. PRO[videntia] A[ugg]. Providentia de peu a esquerra, que sosté vara i cornucòpia; als peus globus.

$3,4 \mathrm{~g} ; 21,8 \mathrm{~mm} ; 7 \mathrm{~h}$.

RIC V.1, 159

Inv.: 3.400

Bibl.: Rosser, 1990; Abascal, 1993

PN'89, cala 10, sec. B, UE 1046

16. GAL·LIÈ. Antoninià. ROMA. 259-268 dC

A. GALLIENVS AVG. Bust radiat amb cuirassa a la dreta.

R. FORTV[n]A REDVX. Fortuna a l'esquerra amb cornucòpia i timó, en camp a la dreta: $\mathrm{S}$.

$3,2 \mathrm{~g} ; 23 \mathrm{~mm} ; 11 \mathrm{~h}$.

RIC V.1, 193; Normanby 217; Cunetio 1215

Inv.: 3.388

Bibl.: Rosser, 1990; Abascal, 1993

PN'88, sector 2C, nivell 3

17. GAL·LIÈ. Antoninià. ROMA. 259-268 dC

A. [gallienu]S AV[g]. Bust radiat amb cuirassa a la dreta.

R. [fort]VNA RED[ux]. Fortuna a l'esquerra amb cornucòpia i timó, en camp a la dreta: $\mathrm{S}$.

$1,5 \mathrm{~g} ; 18 \mathrm{~mm} ; 6 \mathrm{~h}$.

RIC V.1, 193; Normanby 217; Cunetio 1215

Inv.: 3.432

Bibl.: Inèdita

PN'10, B5, UE 1250

Observ.: moneda trencada.

18. CLAUDI II. Antoninià. ROMA o seca local. Post. 270 dC

A. [divo] CLAVD[io]. Cap radiat a la dreta.

R. [c]ONSECR[a]TIO. Altar amb garlanda.

$2,6 \mathrm{~g} ; 19 \mathrm{~mm} ; 6 \mathrm{~h}$.

RIC V.1, 261; Normanby 1113

Inv.: 3.401

Bibl.: Rosser, 1990; Abascal, 1993

PN'89, cala 10, sec. B, UE 1024 
19. SÈRIES URBANES. 1r per. Follis. THESSALONICA, of. 5 a. 330-333 dC

A. V[rbs - roma]. Bust amb casc, ploma i mantell imperial a l'esquerra. R. Lloba amb bessons; dalt, dues estrelles.

Exerg: SM[t]S€

$1,9 \mathrm{~g} ; 18 \mathrm{~mm} ; 12 \mathrm{~h}$.

RIC VII, 187

Inv.: 3.389

Bibl.: Rosser, 1990; Abascal, 1993

PN'88, cala 1, UE 1001

20. CONSTANTÍ II. Nummus. ARELATE. 336-337 dC

A. [c]ONSTANT[i]-NVS IVN N C. Bust llorejat i amb cuirassa a la dreta.

R. [g]LOR[i-a] EX[e]R[ci]TVS. Dos soldats de peu recolzats a les seues llances, entre ells un estendard.

Exerg: $\mathrm{PCO}[\mathrm{nst}]$

$1,1 \mathrm{~g} ; 17,5 \mathrm{~mm} ; 6 \mathrm{~h}$.

RIC VII, 395, 403 o 412

Inv.: 3.413

Bibl.: Inèdita

PN'09, B1, UE 1157

21. CONSTANT. Nummus. CYZICUS. 331/ 333-334 dC

A. [f]L IVL CON[stan]S NO[b c]. Bust d'emperador amb diadema de perles, drapejat i amb cuirassa a la dreta.

R. [g]LOR-[i]A EX[erc]-ITV[s]. Dos soldats de peu recolzats a les seues llances, entre ells dos estendards.

Exerg: [s]MK[a]

$2,2 \mathrm{~g} ; 18,8 \mathrm{~mm} ; 12 \mathrm{~h}$.

RIC VII, 89

Inv.: 3.412

Bibl.: Inèdita

PN'09, B2, UE 1031

22. CONSTANT. Nummus. CYZICUS. $340 \mathrm{dC}$

A. D N [c]ONSTA-NS P [f] AVG. Cap amb diadema de rosetes a la dreta.

R. GLOR-IA EXERC-ITVS. Un estendard.

Exerg: [s]M[ka]?

$1,3 \mathrm{~g} ; 15,4 \mathrm{~mm} ; 12 \mathrm{~h}$.

RIC VIII, 18 ?

Inv.: 3.414

Bibl.: Inèdita

PN'09, UE 1089

23. CONSTANT. Nummus. ROMA. $340 \mathrm{dC}$

A. [d] N F L CON[stans a]VG. Bust amb diadema de llorer i rosetes, drapejat $\mathrm{i}$ amb cuirassa a la dreta.

R. [glor-ia exerc-itus]. Dos soldats de peu recolzats a les seues llances, entre ells un estendard.

Exerg: [r-p]

$1,4 \mathrm{~g} ; 17,2 \mathrm{~mm} ; 10 \mathrm{~h}$.
RIC VIII, pàgs. 249-251

Inv.: 3.433

Bibl.: Inèdita

PN'10, B5, UE 1250

Observ.: la catalogació varia segons la marca de la seca, per aquest motiu oscil-la entre els tipus del RIC VIII, 3, 26, 38, 46A, 49,52 o 58 .

24. CONSTANCI II. Nummus. CONSTANTINOPOLIS, of. 4a. 351-355 dC

A. [d] N CONSTAN-TIVS P F A[ug]. Bust amb diadema de perles, drapejat $\mathrm{i}$ amb cuirassa a la dreta.

R. [fel temp r]-EPARATIO. Soldat a l'esquerra que llanceja un genet caigut.

Exerg: $[\mathrm{c} / \mathrm{a} / / \mathrm{c}] \mathrm{ONS} \Delta$

$2,2 \mathrm{~g} ; 16,2 \mathrm{~mm} ; 12 \mathrm{~h}$.

RIC VIII, 128

Inv.: 3.390

Bibl.: Abascal, 1993

PN'88, cala 7, nivell II, habit. 1

Observ.: segons Abascal RIC VIII, 138.

25. CONSTANCI II. Nummus. ARELATE o CONSTANTINOPOLIS. 351-360 dC

A. D N CONSTAN-[t]IVS P F AVG. Bust amb diadema de perles, drapejat $i$ amb cuirassa a la dreta.

R. FEL TEMP R-[e]PARA[tio]. Soldat a l'esquerra que llanceja un genet caigut.

Exerg: $\mathrm{SC}[\mathrm{on}]$ o $\mathrm{CO}[\mathrm{n}-\mathrm{]}$

$2,1 \mathrm{~g} ; 17,5 \mathrm{~mm} ; 10 \mathrm{~h}$.

RIC VIII, 266 (Arelate) o 123 (Constantinopolis)

Inv.: 3.391

Bibl.: Abascal, 1993

PN'88, cala (magatzem), sector 2, nivell II (prof. -1,11)

26. CONSTANCI II. Nummus. ROMA. 352-355 dC

A. D N CO[nst]AN - TIVS P F AVG. Bust amb diadema de perles, drapejat $\mathrm{i}$ amb cuirassa a la dreta.

R. [fel t]E[mp re] - PARATIO. Soldat a l'esquerra que llanceja un genet caigut.

Exerg: $\mathrm{R} * \mathrm{Q}$

$3,4 \mathrm{~g} ; 23 \mathrm{~mm} ; 6 \mathrm{~h}$.

RIC VIII, 269?

Inv.: 3.392

Bibl.: Abascal, 1993

PN'88, sector E, nivell 2

27. CONSTANCI II. Nummus. ROMA?, of.? 355-361 dC A. D N CONS[tan-ti]VS P F AV[g]. Bust amb diadema de rosetes, drapejat $i$ amb cuirassa a la dreta.

R. [fel temp re -]PARATIO. Soldat a l'esquerra que llanceja un genet caigut.

Exerg: R (corona) P o B? 
$1,6 \mathrm{~g} ; 18,1 \mathrm{~mm} ; 6 \mathrm{~h}$.

RIC VIII, 309?

Inv.: 3.417

Bibl.: Inèdita

PN'09, B2, UE 1036

Observ.: cantell trencat.

28. CONSTANCI II. Nummus. Seca? 350-361 dC

A. [d n con]STA[n-t]IVS P F AV[g]. Bust amb diadema de perles, drapejat i amb cuirassa a la dreta.

R. FEL [te]MP [re]-PARA[tio]. Soldat a l'esquerra que llanceja un genet caigut.

$1,1 \mathrm{~g} ; 16 \mathrm{~mm} ; 6 \mathrm{~h}$.

Inv.: 3.415

Bibl.: Inèdita

PN'09, B3, UE 1184

29. CONSTANCI II. Nummus. Seca? 350-361 dC

A. D N CONSTANT-[ius p f aug]. Bust amb diadema de perles $i$ drapejat a la dreta.

R. [fel temp reparatio]. Soldat a l'esquerra que llanceja un genet caigut.

$2,2 \mathrm{~g} ; 21,5 \mathrm{~mm} ; 3 \mathrm{~h}$.

Inv.: 3.416

Bibl.: Inèdita

PN'09?

Observ.: cantell trencat.

30. CONSTANCI II. Nummus. ARELATE, of.? 355-360 dC A. D N CONST[an - tiu]S P F [aug]. Bust amb diadema de perles, drapejat $\mathrm{i}$ amb cuirassa a la dreta.

R. [spe]S R[ei-]PVBLICE. Emperador de peu a l'esquerra, que sosté globus i llança.

Exerg: [-]CON

$1,9 \mathrm{~g} ; 17,4 \mathrm{~mm} ; 12 \mathrm{~h}$.

RIC VIII, 275?

Inv.: 3.418

Bibl.: Inèdita

PN'09, B1, UE 1031?

31. CONSTANCI II o JULIÀ. Nummus. Seca? 355-363 dC

A. [---]. Bust amb diadema de perles i drapejat a la dreta.

R. [s]PES R[ei-publice]. Emperador de peu a l'esquerra, que sosté globus i llança.

$1,4 \mathrm{~g} ; 15,5 \mathrm{~mm} ; 7 \mathrm{~h}$.

Inv.: 3.393

Bibl.: Abascal, 1993

PN'88, sector C, nivell 2

32. CONSTANCI II o JULIÀ. Nummus. Seca? 355-363 dC

A. [---]. Bust amb diadema de perles, drapejat i amb cuirassa a la dreta.

R. [spes rei-publice]. Emperador de peu a l'esquerra, que sosté globus i llança.

$2,2 \mathrm{~g} ; 19,5 \mathrm{~mm} ; 12 \mathrm{~h}$.

Inv.: 3.419

Bibl.: Inèdita

PN'09, B1, UE 1037, per. ref.

Observ.: cantell trencat.

\section{CONSTANCI I, CONSTANTÍ I, CONSTANCI II? Nummus.} Seca? s. IV dC

A. F L [---] CONSTAN[---]. Bust amb diadema de perles a la dreta.

R. Il-legible.

$1,5 \mathrm{~g} ; 16,2 \mathrm{~mm}$; -

Inv.: 3.420

Bibl.: Inèdita

PN'09, B2, UE 1036

34. GRACIÀ. Nummus. ARELATE, of. 1a. 378-383 dC

A. D N [gra]TI[a] - NVS [p f a]V[g]. Bust amb diadema de perles, drapejat $\mathrm{i}$ amb cuirassa a la dreta.

R. V[o]T/ [xv]/ MVLT/ XX. Llegenda dins de corona de llorer.

Exerg: $[\mathrm{p}] \mathrm{CO}[\mathrm{n}]$

$1,7 \mathrm{~g} ; 15 \mathrm{~mm} ; 12 \mathrm{~h}$

RIC IX, 24

Inv.: 3.394

Bibl.: Rosser, 1990; Abascal, 1993

PN'88, sector E, nivell 1

\section{ATRIBUCIÓ INDETERMINADA}

TIPUS GLORIA EXERCITUS

35. ATRIBUCIÓ INDETERMINADA. Nummus. Seca? 330$336 \mathrm{dC}$

A. [---] MAX AV [g]. Bust d'emperador amb diadema de perles, drapejat $i$ amb cuirassa a la dreta.

R. [gloria exercitus?]. Dos soldats de peu recolzats a les seues llances, entre ells dos estendards.

$1,9 \mathrm{~g} ; 15,5 \mathrm{~mm} ; 6 \mathrm{~h}$.

Inv.: 3.424

Bibl.: Inèdita

PN'09, B, UE 1038

36. ATRIBUCIÓ INDETERMINADA. Nummus. Seca? 335$340 \mathrm{dC}$

A. [---]. Bust amb diadema de perles a la dreta.

R. [gloria exercitus]. Dos soldats de peu recolzats a les seues llances, entre ells un estendard.

$1,7 \mathrm{~g} ; 19 \mathrm{~mm} ; 10 \mathrm{~h}$.

Inv.: 3.397

Bibl.: Inèdita

PN'88, Cala -- NI (+ 0’44)

Observ.: moneda partida. 
37. ATRIBUCIÓ INDETERMINADA. Nummus. Seca? 335$340 \mathrm{dC}$

A. [---] V[---]. Bust amb diadema de perles i drapejat a la dreta.

R. [g]LO[ria exercitus]. Dos soldats de peu recolzats a les seues llances, entre ells un estendard (?).

$1,8 \mathrm{~g} ; 13,5 \mathrm{~mm} ; 5 \mathrm{~h}$.

Inv.: 3.425

Bibl.: Inèdita

PN'09, A1, UE 1076

TIPUS FALLING HORSEMAN

38. ATRIBUCIÓ INDETERMINADA. Nummus. Seca? 350$361 \mathrm{dC}$

A. [---]. Bust d'emperador amb diadema de perles, drapejat i amb cuirassa a la dreta.

R. [fel temp reparatio?]. Soldat a l'esquerra que llanceja un genet caigut.

$2,3 \mathrm{~g} ; 16,8 \mathrm{~mm} ; 1 \mathrm{~h}$.

Inv.: 3.421

Bibl.: Inèdita

PN'09, B, UE 1038?

39. ATRIBUCIÓ INDETERMINADA. Nummus. Seca? 350$361 \mathrm{dC}$

A. [---]. Bust amb diadema de perles i drapejat a la dreta.

R. [fel temp reparatio?]. Soldat a l'esquerra que llanceja un genet caigut.

$1,3 \mathrm{~g} ; 15 \mathrm{~mm} ; 1 \mathrm{~h}$.

Inv.: 3.438

Bibl.: Inèdita

PN'10, B5, UE 1246

40. ATRIBUCIÓ INDETERMINADA. Nummus. Seca? s. IV dC

A. [---]. Bust amb diadema de perles a la dreta.

R. [fel temp reparatio? o gloria exercitus].

$1,1 \mathrm{~g} ; 12 \mathrm{~mm}$; -

Inv.: 3.440

Bibl.: Inèdita

PN'10, B2, UE 1242

ALTRES TIPUS

41. ATRIBUCIÓ INDETERMINADA. Nummus. Seca? 337$351 \mathrm{dC}$

A. [---]. Bust amb diadema de perles i drapejat a la dreta.

R. [victoria augusti?]. Victòria avançant a l'esquerra, du corona i palma.

2,2 g; $15 \mathrm{~mm} ; 6 \mathrm{~h}$.

Inv.: 3.428

Bibl.: Inèdita

PN'09, A1, UE 1129
42. ATRIBUCIÓ INDETERMINADA. Nummus. Seca? 1a meitat s. IV dC

A. D N CON[---]. Bust amb diadema de perles a la dreta.

R. III (?). Il-legible.

$1,6 \mathrm{~g} ; 13,2 \mathrm{~mm}$; -

Inv.: 3.439

Bibl.: Inèdita

PN'10, B5, UM 1225 (neteja mur?)

Observ.: cospell desplaçat.

43. ATRIBUCIÓ INDETERMINADA. Nummus. Seca? s. IV dC A. [---]. Bust amb casc?, drapejat i amb cuirassa a la dreta.

R. [--- roman---]. Figura amb toga a la dreta, que sosté amb la mà dreta una bola o casc i amb l'esquerra la pròpia toga (?).

$1,8 \mathrm{~g} ; 15 \mathrm{~mm} ; 6 \mathrm{~h}$.

Inv.: 3.422

Bibl.: Inèdita

PN'09, B5, UE 1096

44. ATRIBUCIÓ INDETERMINADA. Nummus. Seca? ss. IV-V dC

A. [---]. Cap a la dreta.

R. Il·legible.

$1,1 \mathrm{~g} ; 14 \mathrm{~mm}$; -

Inv.: 3.437

Bibl.: Inèdita

PN'10, B5, UE 1246

45. ATRIBUCIÓ INDETERMINADA. Nummus. Seca? ss. IV-V dC

A. [---] AV [---]. Bust d'emperador amb diadema de perles a la dreta.

R. Il-legible.

- g; 15,5 mm; -

Inv.: 3.426

Bibl.: Inèdita

PN'09; B1; UE 1019

46. ATRIBUCIÓ INDETERMINADA. Nummus. Seca? ss. IV-V dC

A. [---]. Bust amb diadema de perles i drapejat a la dreta.

R. Figura de peu.

$1,9 \mathrm{~g} ; 13,6 \mathrm{~mm} ; 4 \mathrm{~h}$.

Inv.: 3.427

Bibl.: Inèdita

PN'09?

47. ATRIBUCIÓ INDETERMINADA. Nummus. Seca? ss. IV-V dC

A. [---]. Bust d'emperador amb diadema de perles a la dreta.

R. Il·legible.

$2,2 \mathrm{~g} ; 17 \mathrm{~mm}$; -

Inv.: 3.423 
Bibl.: Inèdita

PN'09, B, UE 1038

\section{INDETERMINADES}

48. INDETERMINADA. As. Seca? ss. I-II dC

Anvers i revers il·legibles.

$5,9 \mathrm{~g} ; 26,2 \mathrm{~mm}$; -

Inv.: 3.429

Bibl.: Inèdita

PN'09, A6, UE 1071

49. INDETERMINADA. Nummus. Seca? ss. IV-V dC Anvers i revers il-legibles.

$1,4 \mathrm{~g} ; 13,5 \mathrm{~mm}$; -

Inv.: 3.445

Bibl.: Inèdita

PN'88?, cala 13, UE 3001

50. INDETERMINADA. Nummus? Seca? ss. IV-V dC Anvers i revers il·legibles.

$0,9 \mathrm{~g} ; 12,5 \mathrm{~mm}$; -

Inv.: 3.395

Bibl.: Abascal, 1993
PN'88, sector 2C, nivell 3

Observ.: partida en 3 trossos.

51. INDETERMINADA. Nummus? Seca? ss. IV-V dC Anvers i revers il-legibles.

$2,0 \mathrm{~g} ; 20,1 \mathrm{~mm}$; -

Inv.: 3.436

Bibl.: Inèdita

PN'10, B2, UE 1242

Observ.: cantell trencat.

52. INDETERMINADA. Nummus. Seca? ss. IV-V dC Anvers i revers il-legibles.

$2,5 \mathrm{~g} ; 16 \mathrm{~mm}$; -

Inv.: 3.435

Bibl.: Inèdita

PN'10, B2, UE 1242

53. INDETERMINADA. Nummus? Seca? ss. IV-V dC Anvers i revers il-legibles.

$1,6 \mathrm{~g} ; 15,5 \mathrm{~mm}$; -

Inv.: 3.434

Bibl.: Inèdita

PN'10, B2, UE 1242
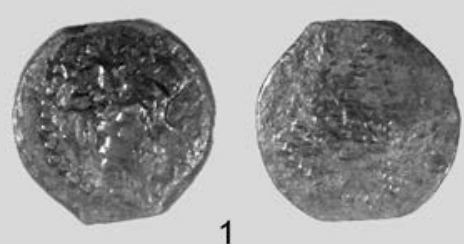

1

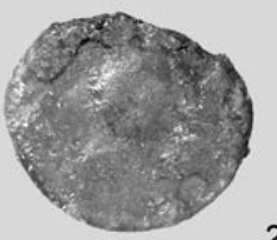

2
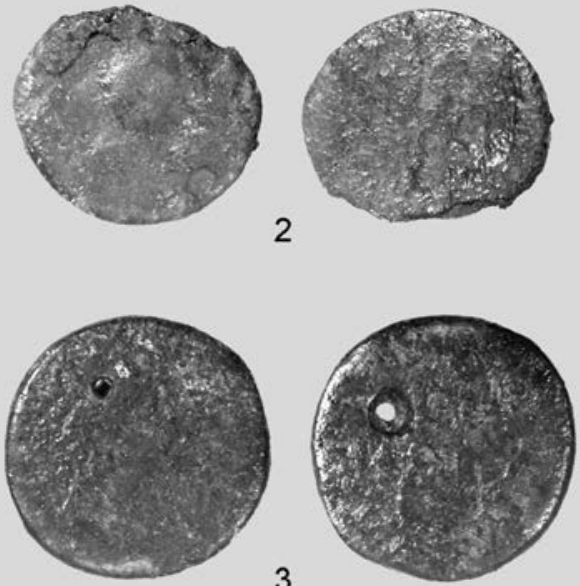
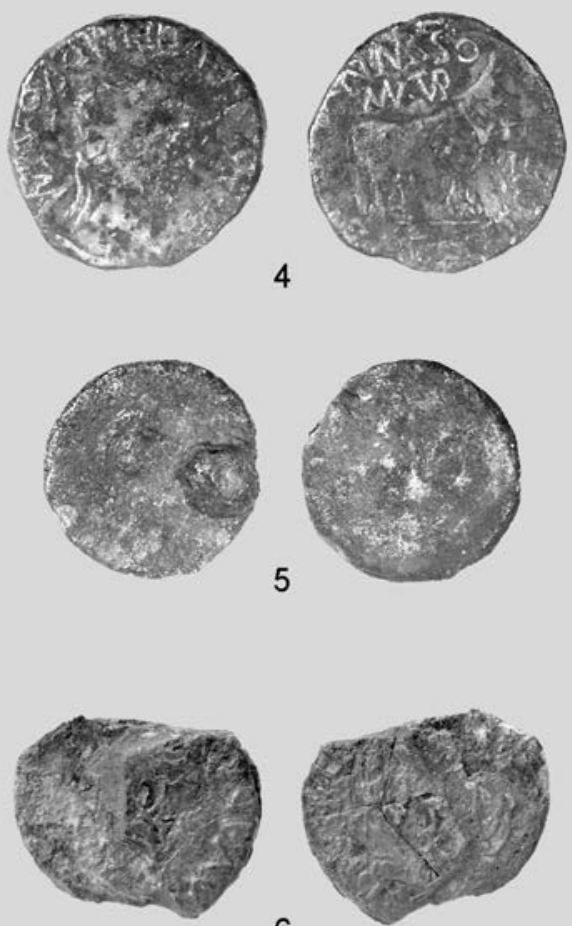

6 

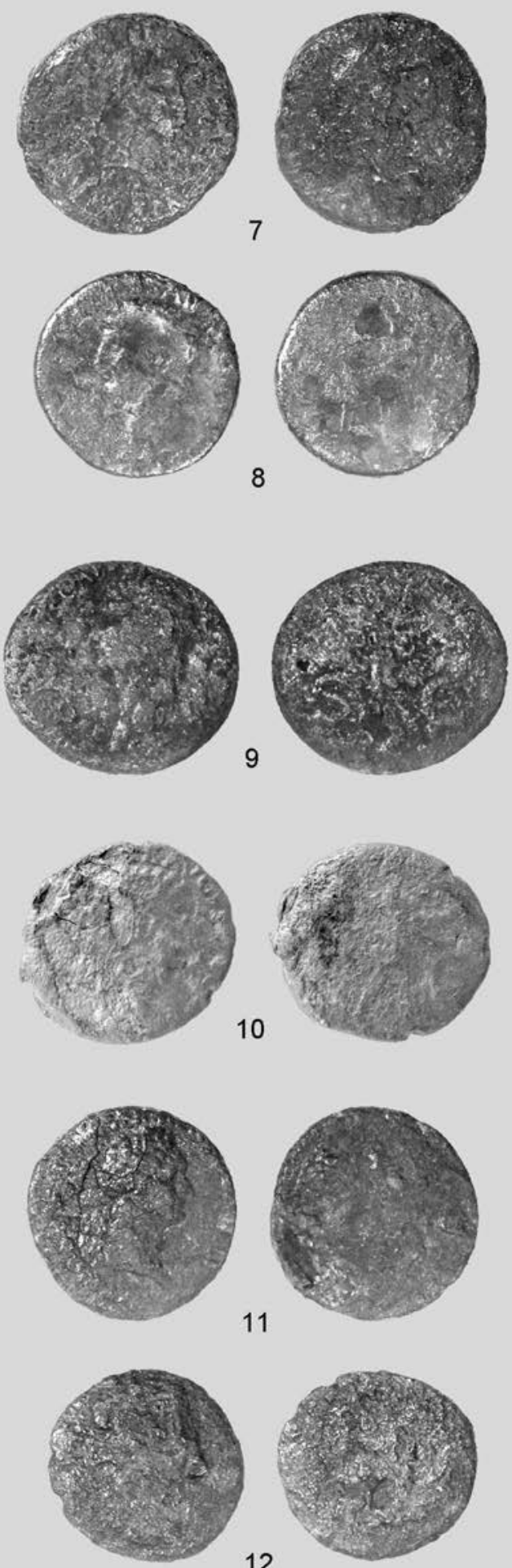

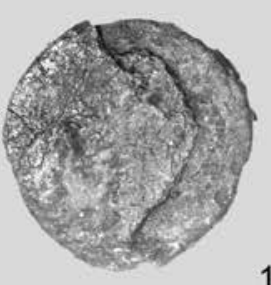

13
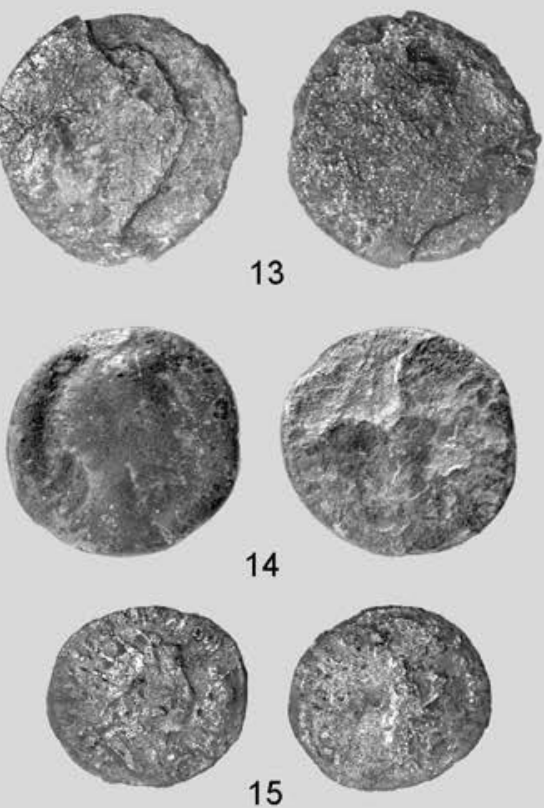

15
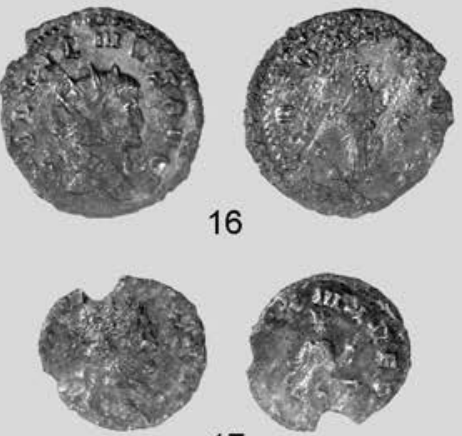

17
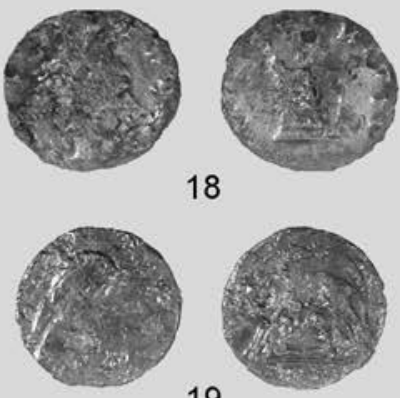

19

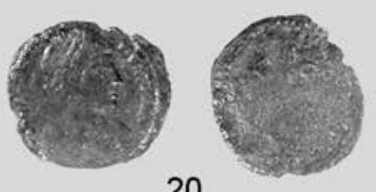

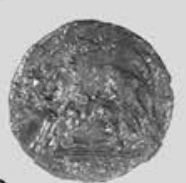




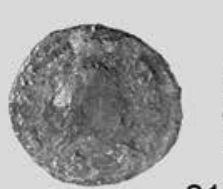

21
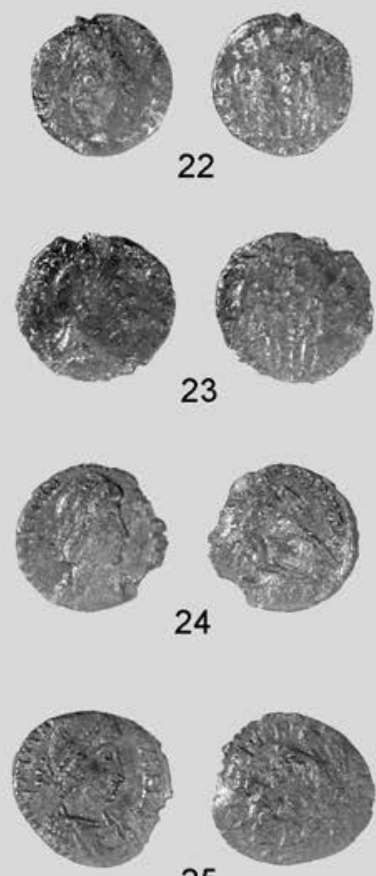

25

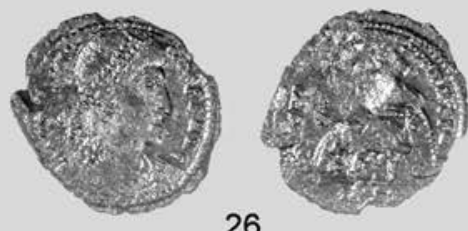

26

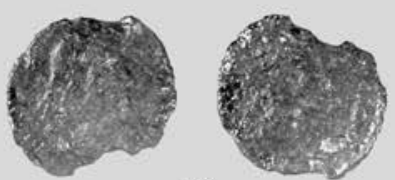

27

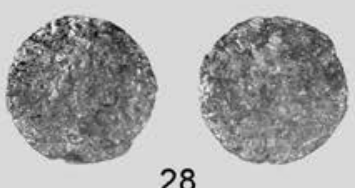

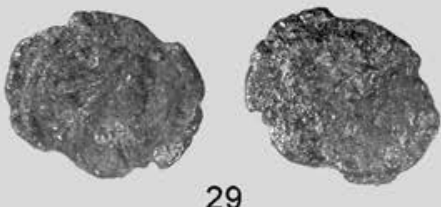

29
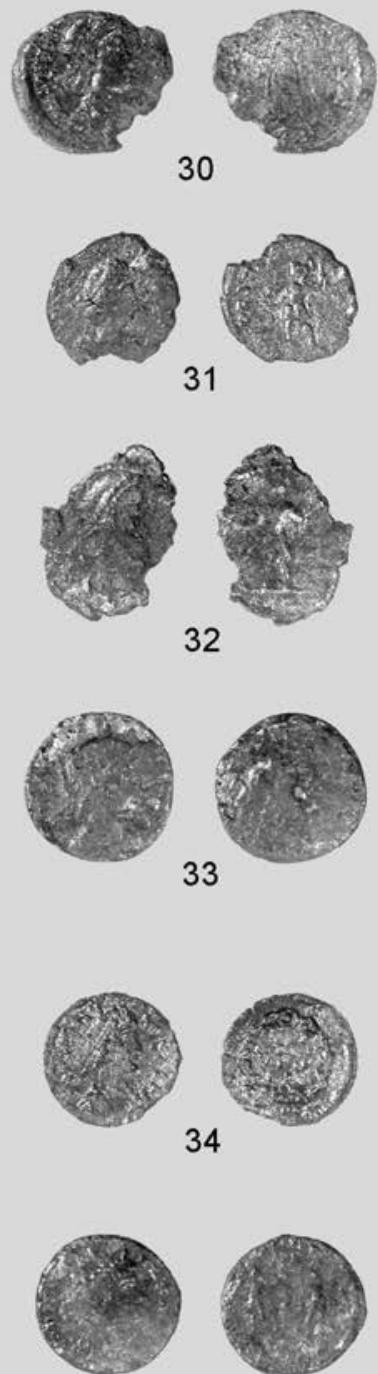

35

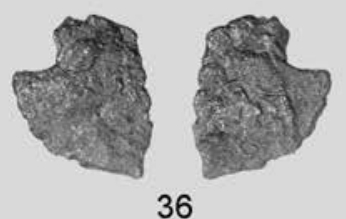




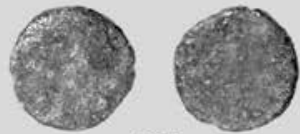

37

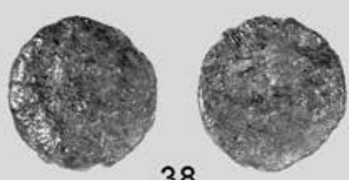

38

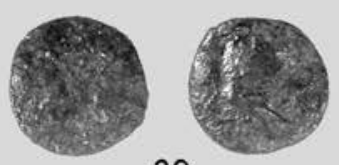

39

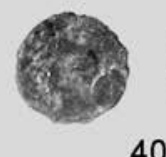

40

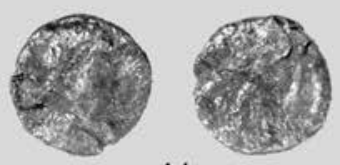

41

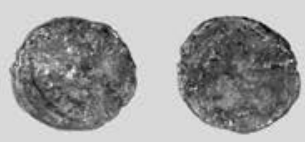

42

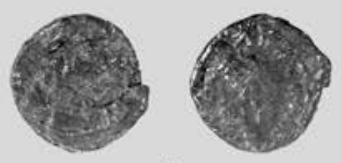

43

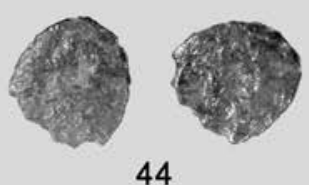

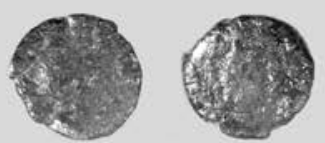

46
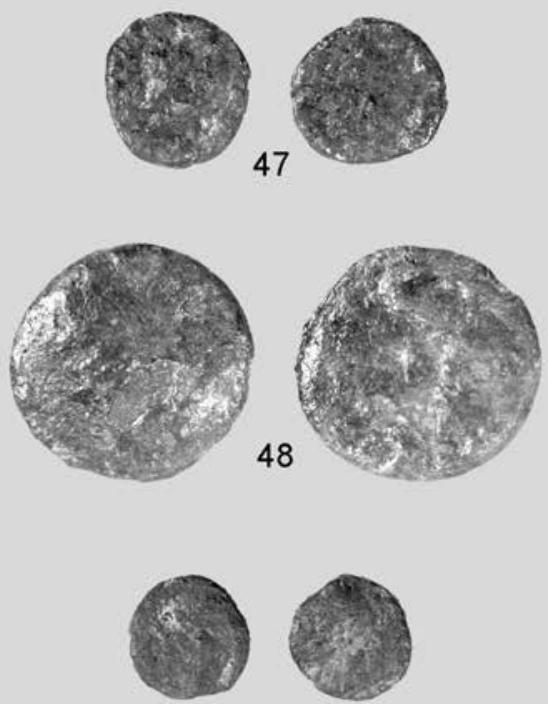

49

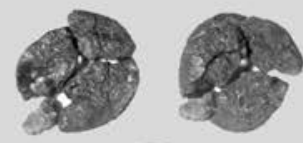

50

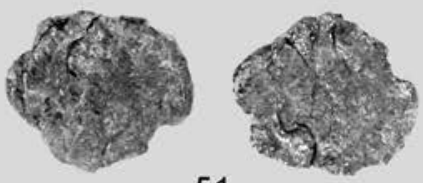

51
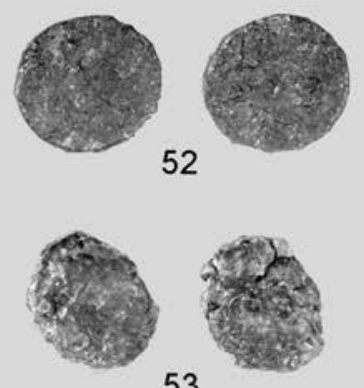

53 


\section{NOTA}

1. Volem expressar el nostre agraïment a C. Fuentes i J. Giménez per possibilitar la realització de l'estudi següent. A J. J. Ramón, del MARQ, que ens ha facilitat informació sobre el material i les publicacions existents a la institució. A P. Luque pe part de l'ajuda gràfica, T. Hurtado pels consells i suggeriments, i J. A. Mellado pel seu suport. Així mateix, volem agrair els comentaris dels revisors anònims que, dins les possibilitats existents, hem incorporat al text $\mathrm{i}$ han contribuït a polir una part del resultat final.

\section{BIBLIOGRAFIA}

ABASCAL, J. M. (1989): La circulación monetaria del Portus Ilicitanus, València

ABASCAL, J. M. (1993): Hallazgos epigráficos y numismáticos en las excavaciones del área del Tossal de Manises (19871990), LQNT 1, 137-152.

ABASCAL, J.M. (2002): La fecha de la promoción colonial de Carthago Noua y sus repercusiones edilicias, Mastia 1, 21-44.

ABASCAL, J. M. (2004): Colonia Iulia Ilici Augusta. Iberia, Hispania, Spania. Una mirada desde Ilici, Alacant, 79-94.

ABASCAL, J. M.; GISBERT, J. A. (1990-1991): Numismática y evidencia arqueológica en el alfar romano de la Almadrava (Setla-Mirarosa-Miraflor), Lucentum IX-X, 133-160.

ABASCAL, J. M.; ALBEROLA, A. (2007): Monedas antiguas de los museos de Elche. Real Academia de la Historia, Gabinete de Antigüedades, Madrid.

ABASCAL, J. M.; ALBEROLA, A. (2010): Hallazgos monetarios en Calpe ( $2^{\mathrm{a}}$ serie), Lucentum XXIX, 163-186.

ABASCAL, J. M.; CEBRIÁN, R.; RONDA, A.; SALA, F. (eds.) (2007): Baños de la Reina (Calpe, Alicante). Un vicus romano a los pies del Peñón de Ifach, Calp.

ALBEROLA, A.; ABASCAL, J. M. (1998): Moneda antigua y vida económica en las comarcas del Vinalopó, València.

ALFARO, C. (1997): La emisiones feno-púnicas, Historia monetaria de Hispania Antigua, Madrid, 50-115.

ARANEGUI, C.; JODIN, A.; LLOBREGAT, E. A.; ROUILLARD, P.; UROZ. J. (1993): La nécropole ibérique de Cabezo Lucero (Guardamar del Segura, Alicante), Collections de la Casa de Velázquez 41. Colección Patrimonio 17, Madrid-Alacant.

ARIAS, L. (2006): La Circulación Monetaria en el Levante Peninsular durante el siglo II d.C., Fundació Municipal "José M" Soler", Villena.

ARROYO, R. (1982): Volumen y repercusión de la inflación monetaria romana del 261-269 d.C. en la Tarraconense Costera Meridional, Sagvntvm-PLAV 17, 131-145.

ARROYO, R. (1985): El tesorillo de monedas tardorromanas de Monforte (Alacant), Acta Numismàtica 15, 139-156.

ARROYO, R. (1988): Estudio numismático del yacimiento tardorromano del Albir (Altea-Alacant), Acta Numismàtica 17$18,153-172$.
ARROYO, R.; BOLUFER, J. (1988): Anàlisi numismàtica del conjunt monetari de la Punta de l'Arenal (col-lecció Segarra Llamas), Xàbiga 4, 25-37.

BARAHONA, Z.; MOLINOS, N. I. (2010): Memoria final de la excavación arqueológica del Parque de las Naciones. Campaña noviembre 2009 - abril 2010.

CALICÓ, X. (2008): Numismática Española. Catálogo de todas las monedas emitidas desde los Reyes Católicos hasta Juan Carlos I, 1474 a 2001, Barcelona.

CAMPO, M. (1976): Las monedas de Ebusus, Barcelona.

CAMPO, M. (1993): Las monedas de Ebusus, VII Jornadas de arqueología Fenicio-Púnica (Eivissa, 1992), 147-171.

CAMPO, M. (1999): Els exèrcits i la monetització d'Hispània (218$45 \mathrm{aC})$, III Curs d'Història monetària d'Hispània. Moneda i exèrcits, MNAC, Barcelona, 59-81.

CAMPO, M. (2013a): La moneda de Ebusus y su proyección mediterránea, Ebusus y Pompeya, ciudades marítimas. Testimonios monetales de una relación, 61-81.

CAMPO, M. (2013b): De donde venían y a donde iban las monedas fenicio-púnicas. Producción, función y difusión de las emisiones, XXVII Jornadas de arqueología Fenicio-Púnica (Eivissa, 2012), La moneda y su papel en las sociedades fenicio-púnicas, 9-33.

CAMPO, M. (2014): La fase inicial de la ceca de Ybshm/Ebusus (siglo IV a.C.), In Amicitia. Miscel-lània d'estudis en homenatge a Jordi H. Fernández (C. Ferrando, B. Costa, eds.), Eivissa, 133-148.

CNH = VILLARONGA, L. (1994): Corpus Nummum Hispaniae Ante Augusti Aetatem, Madrid.

Cunetio = BESLY, E.; BLAND, R. (1983): The Cunetio Treasure. Roman Coinage of the Third Century AD, Londres.

FRÍAS, C. (2010): El poblamiento rural de Dianium, Lucentum, Ilici y la ciudad romana de la Vila Joiosa (siglos II a.C.VII d.C.). Bases para su estudio, Alacant.

FRÍAS, C.; LLIDÓ, F. (2005): Evolución de las actividades comerciales en la factoría de salazones de Picola-Portus Ilicitanus (Santa Pola, Alicante): Análisis numismático, Actes del III Congreso internacional de estudios históricos. El mediterráneo: la cultura del mar y la sal, Santa Pola, 205-219.

GARCÍA, A. M.; OLCINA, M. H.; RAMÓN, J. J. (2010): Un nivel de amortización de una cloaca de Lucentum (Tossal de Manises, Alicante), Rei Cretariae Romanae Fautorum Acta 41, 353-362.

GARRIGÓS, I. (2013a): El MUSA (Museo de la Ciudad de Alicante) y sus fondos numismáticos, Mansio. Revista de Arqueología y Patrimonio Cultural 1, 39-58, <http:// www.academia.edu/4254815/Revista_Mansio_julio_2013> (Consulta 27-VI-2015).

GARRIGÓS, I. (2013b): Les monedes de la vil·la romana de Casa Ferrer I als fons del MUSA (Museu de la ciutat d'Alacant), Lucentum XXXII, 171-183. DOI: https://doi.org/10.14198/LVCENTVM2013.32.08 
GARRIGÓS, I.; MELLADO, J. A. (2004): Les monedes de la Serreta: consideracions sobre la circulació monetària a les comarques meridionals del País Valencià, Recerques del Museu d'Alcoi 13, 201-226.

GARRIGÓS, I.; SANTOS-OLMO, J. (2015): Monedes de jaciments i troballes fortuïtes al Museu Arqueològic Municipal d'Alcoi, Recerques del Museu d'Alcoi 24, 149-186.

GONZÁLEZ, A.; ABASCAL, J. M. (1987): La ocultación monetal de la d'Eula, Crevillente (Alicante) y su significación para el estudio de las invasiones del siglo III, Lucentum VI, 183-196.

GOZALBES, M. (2009): La ceca de Turiazu. Monedas celtibéricas en la Hispania republicana, Sèrie Treballs Varis. S.I.P. 110 , València.

HURTADO, T. (2006): Una moneda de Claudio II en la Falguera, El Abric de la Falguera (Alcoi, Alacant). 8000 años de ocupación humana en la cabecera del río de Alcoi (O. García, J. E. Aura, coords.), Alcoi, 272-273.

LARA, G.; GARCÍA, J.; LÓPEZ, E.; RIZO, C. E.; SÁNCHEZ, M. D. (2007): Nuevas evidencias de la ocupación de Benalúa (Alicante) durante los siglos VI-VII d.C., MARQ, Arqueología y Museos 2, 49-81.

LLEDÓ, N. (2010): El uso monetario en Alicante durante el período romano imperial y la época tardoantigua, Monedas, todas las caras de la historia. Colecciones numismáticas del $M A R Q, 28-43$.

LLOBREGAT, E. A. (1972): Contestania ibérica, Alacant.

LLORENS, M. M. (1987): La ceca de Ilici, València.

LLORENS, M. M. (1994): La ciudad de Carthago Noua: las emisiones romanas, Múrcia.

LLORENS, M. M. (2002): Carthago Noua: una ceca provincial romana con vocación comercial, Mastia 1, 45-76.

MAROT, T. (2000-2001): La Península Ibérica en los siglos V-VI: consideraciones sobre provisión, circulación y usos monetarios, Pyrenae 31-32, 133-160.

MAROT, T.; SALA, F.; LLORENS, M. M. (2000): Contextos monetarios del siglo VI: las monedas procedentes de los vertederos del barrio de Benalúa (Alicante), Actes de la $\mathrm{V}$ Reunió d'Arqueologia Cristiana Hispànica (Cartagena, 1998), 507-518.

Normanby = BLAND, R.; BURNETT, A. (ed.) (1988): The Normanby Hoard and other Romans coin hoards. Coin Hoards from Roman Britain VIII, Londres.

MELLADO, J. A.; GARRIGÓS, I. (2008): La circulació monetària a les comarques alacantines en època ibèrica: l'exemple del jaciment del Xarpolar, Actes del I Congrés de Joves Investigadors en Arqueologia dels Països Catalans: la protohistòria als Països Catalans (M. Miñarro, S. Valenzuela, eds.), Arqueomediterrània 10, 201-204.

MOLINOS, N. I. (2012): Villa romana del Parque de las Naciones. Solares Av. Miriam Blasco, 5 - C/ Palas Atenea, 7 - C/ Afrodita, 2-19-23. Prolongación de los sectores B2, B3 y $B 5$ (Alicante), Intervenciones arqueológicas en la provincia de Alicante, 2011 (publicació digital).
OLCINA, M. H.; PÉREZ, R. (2003): Lucentum: la ciudad y su entorno, Las ciudades y los campos de Alicante en época romana, Canelobre 48, 90-119.

RAMÓN, J. J. (2002): El hallazgo de moneda hispano-cartaginesa de La Escuera (Alicante), Actas del X Congreso Nacional de Numismática (Albacete, 1998), 243-251.

RAMÓN, J .J. (2009): Monedas de ceca hispano-latina en la ciudad romana de Lucentum (Alicante), Actas del XIII Congreso Nacional de Numismática (Cadis, 2007), vol. I, 413-433.

RAMÓN, J. J. (2010): Las colecciones numismáticas del MARQ de Alicante, Monedas, todas las caras de la historia. Colecciones numismáticas del MARQ, Alacant, 80-91.

RAMÓN, J. J.; GARCÍA, A.; VERDÚ, E.; BAYO, S. (2010): Catálogo. Antigüedad, Monedas, todas las caras de la historia. Colecciones numismáticas del MARQ, Alacant, 95-127.

RIPOLLÈS, P. P. (1980): La circulación monetaria en las tierras valencianas durante la Antigüedad, Barcelona.

RIPOLLÈS, P. P. (1982): La circulación monetaria en la Tarraconense Mediterránea, SIP, Sèrie de Treballs Varis, 77, València.

RIPOLLÈS, P. P. (1997): Las acuñaciones cívicas romanas de la Península Ibérica (44 a.C.-54 d.C.), Historia monetaria de Hispania Antigua, Madrid, 335-395.

RIPOLLÈS, P. P. (2007): Las acuñaciones de la ciudad ibérica de Saitabi, València.

RIPOLLÈS, P. P. (2010): La circulación monetaria en Alicante hasta la época imperial, Monedas, todas las caras de la historia. Colecciones numismáticas del MARQ, 16-27.

RONDA, A. (1993): Aproximación al estudio del registro cerámico de las excavaciones arqueológicas de urgencia realizadas por el COPHIAM en la villa romana -Parque de las Naciones- (Albufereta, Alicante), LQNT 1, 167-179.

ROSSER, P. (1990): Nuevos descubrimientos arqueológicos en el término municipal de Alicante, Historia de la ciudad de Alicante. Edad Antigua, vol. I, Alacant, 190-285.

ROSSER, P. (1990-1991): La necrópolis romana alto-imperial del "Parque de las Naciones" (Albufereta, Alicante): estudio de alguno de sus materiales, Lucentum IX-X, 85-102.

ROSSER, P. (1994): Nuevas aportaciones a la problemática de la antigüedad tardía en Alicante, LQNT 2, 69-110.

ROSSER, P.; SÁEZ, J.; ROCHE, J. A. (1992): El misterio de la villa romana del Parque de las Naciones, Dossier para profesores. C.A.P.A.V. - Ajuntament d'Alacant. Alacant.

ROSSER, P. (coord.) (2007): El patrimonio cultural de Alicante: avance de un catálogo. El patrimonio inmueble, LQNT, Monogràfic 3.

ROSSER, P.; MOLINOS, N. I. (2011): Informe preliminar. Villa romana del Parque de las Naciones. Campaña 2010-2011

ROYO, M. M. (2009): El emperador Juliano II y el programa iconográfico de sus monedas, Documenta \& Instrumenta 7 , 161-186. 
RIC I = SUTHERLAND, C. H. V.; CARSON, R. A. G. (1984): The Roman Imperial Coinage, vol. I, from 31 BC to $A D 69$, Londres.

RIC II = MATTINGLY, H.; SYDENHAM, E. (1926): The Roman Imperial Coinage, vol. II, Vespasian to Hadrian, Londres. RIC V.1 = MATTINGLY, H.; SYDENHAM, E.; WEBB, P. (1927): The Roman Imperial Coinage, vol. V, Part I, Londres.

RIC VII = SUTHERLAND, C. H. V.; CARSON, R. A. G.; BRUUN, P. (1966): The Roman Imperial Coinage, vol. VII, Constantinus to Licinius, A.D. 313-337, Londres.

RIC VIII = SUTHERLAND, C. H. V.; CARSON, R. A. G. (1981) The Roman Imperial Coinage, vol. VIII, The family of Constantine I, Londres.
RIC IX = MATTINGLY, H.; SUTHERLAND, C.; PEARCE, J. (1951): The Roman Imperial Coinage, vol. IX, Valentinian I to Theodosius I, Londres.

$R P C=$ BURNETT, A.; AMANDRY, M.; RIPOLLÈS, P. P. (1992) Roman Provincial Coinage, vol. I, From the death of Caesar to Vitellius (44 BC to AD 69), Londres- París.

$R R C=$ CRAWFORD, M. H. (1974): Roman Republican Coinage, Cambridge.

VERDÚ, E. (2010): Sobre la presencia de monedas púnicas en sepulturas de la necrópolis de l'Albufereta (Alacant), Mainake XXXII 1, 301-333.

VISEDO, C. (1959): Alcoy. Geología. Prehistoria, Alcoi.

Vives = VIVES, A. (1926): La moneda hispánica, Madrid. 